\title{
INTERACCIONES Y LENGUAJES VISUALES EN LA CERÁMICA LOCAL DE LOS PERÍODOS INCA Y COLONIAL (CENTRO OESTE ARGENTINO)
}

\author{
INTERACTIONS AND VISUAL LANGUAGES IN LOCAL POTTERY OF INCA AND COLONIAL \\ PERIODS (WEST-CENTRAL ARGENTINA)
}

\author{
Cristina Prieto-Olavarría ${ }^{1}$ V Vanina Tobar ${ }^{2}$
}

\begin{abstract}
Resumen
El estudio de la cerámica producida localmente en áreas fronterizas del dominio incaico permite investigar la circulación de personas y de conocimiento en esos sectores. Además, posibilita definir el rol que cumplieron las vasijas producidas localmente, tanto en la dominación simbólica imperial como en las estrategias surgidas entre las poblaciones dominadas. En este trabajo analizamos el caso de la cerámica Viluco, la que fue producida en la frontera meridional oriental incaica (Centro Oeste Argentino) y se encuentra en contextos coloniales hasta el siglo

XVII. El estudio de las formas, decoraciones modeladas y el análisis exhaustivo de los patrones de simetría que estructuraron la decoración pintada, permitieron definir con mayor precisión las influencias recibidas por parte de diversas tradiciones cerámicas del Área Andina; cómo las poblaciones locales encontraron medios indirectos de representación en los nuevos contextos de relaciones de poder; y de qué modo la cerámica Viluco formó parte de los sistemas de representación visual inca, función que se proyectó hasta los primeros años de la Colonia.
\end{abstract}

Palabras claves: Área Andina Meridional - dominación inca - Colonia cerámica Viluco - análisis de simetría.

\begin{abstract}
The study of locally made pottery in peripheral regions of Inca domination can reveal past movements of people and knowledge that occurred through various pottery styles and manufacturing techniques. In addition, it can reveal the role that locally-made vessels played, both in imperial symbolic domination and strategies that emerged among

dominated populations. In this work, we present the case of Viluco pottery from the south-eastern frontier of Inca domination (west-central

Argentina), which has also been found in colonial contexts until the

XVII century. The shapes, decorative applications, and patterns of symmetry that structured painted decorations allow us to more precisely define the influences from various ceramic traditions found throughout the Andean region; how local populations developed indirect methods of representation in the context of new power relations; and how Viluco pottery entered into the Inca system of visual representation, taking on a role that continued until the early years of Spanish colonization.
\end{abstract}

Keywords: Meridional Andean Area - inca domination - Colony - Viluco pottery - symmetry analysis.

Recibido: enero 2016. Aceptado: marzo 2017

\section{* Introducción}

Los símbolos asociados al dominio inca o Tawantinsuyu fueron desplegados en diversos soportes materiales. La recurrente presencia de cerámica local en los contextos arqueológicos relacionados con el Incario, hacen de ella un importante objeto de estudio para analizar la dominación en las áreas alejadas del núcleo imperial. En efecto, una de las estrategias de conquista y dominio fue la apropiación simbólica de los territorios anexados a través de los objetos, y la cerámica uno de los soportes utilizados para tal fin (Bray 2003; Cummins 2002, 2007; D’Altroy et al. 1994; González Carvajal y Bray 2008; Williams 2008).

El sur de la provincia de San Juan, y el norte y centro de la provincia de Mendoza, forman el Centro Oeste Argentino (COA en lo que sigue de este trabajo), el que fue el límite meridional oriental de la expansión inca (Figura 1). Su carácter periférico y fronterizo se refleja, entre otros aspectos, en la escasa presencia de objetos suntuarios, como la cerámica inca imperial, textiles ${ }^{3}$ y elementos de metal, los que circularon desde el centro del Tawantinsuyu y fueron vitales en la mediación comunicacional y las interacciones entre el Estado y los grupos dominados (Bray 2004; D'Altroy et al. 1994; Williams 2008). En este contexto, la cerámica Viluco (Lagiglia 1978), un tipo Inca Mixto (Ots 2008; Raffino 1981) producido por la población local y hallado en contextos de los siglos XV, XVI y XVII, habría sido relevante para el sostenimiento de las relaciones entre dominados y entre éstos y los dominadores incas y españoles, especialmente en las tierras bajas del norte y centro de Mendoza (valles del

1 Consejo Nacional de Investigaciones Científicas y Técnicas, Instituto Argentino de Nivología, Glaciología y Ciencias Ambientales, CCT-Mendoza. Argentina. Av. Ruiz Leal s/n Parque General San Martín. Casilla de correo 330. Mendoza, CP 550o, ARGENTINA. Email: cprieto@ mendoza-conicet.gob.ar

2 Centro de Investigaciones Ruinas de San Francisco, Área Fundacional, Municipalidad de Mendoza. Ituzaingó 2134. Mendoza, CP 5500, ARGENTINA.Email: vantob3@yahoo.com.ar

3 En el área se recuperaron textiles de la dominación inca, mantos finos o cumbi, que formaron parte del fardo funerario de las momias halladas en Mendoza y San Juan (Abal de Russo 2010; Michieli 1990; Schobinger 2001). 


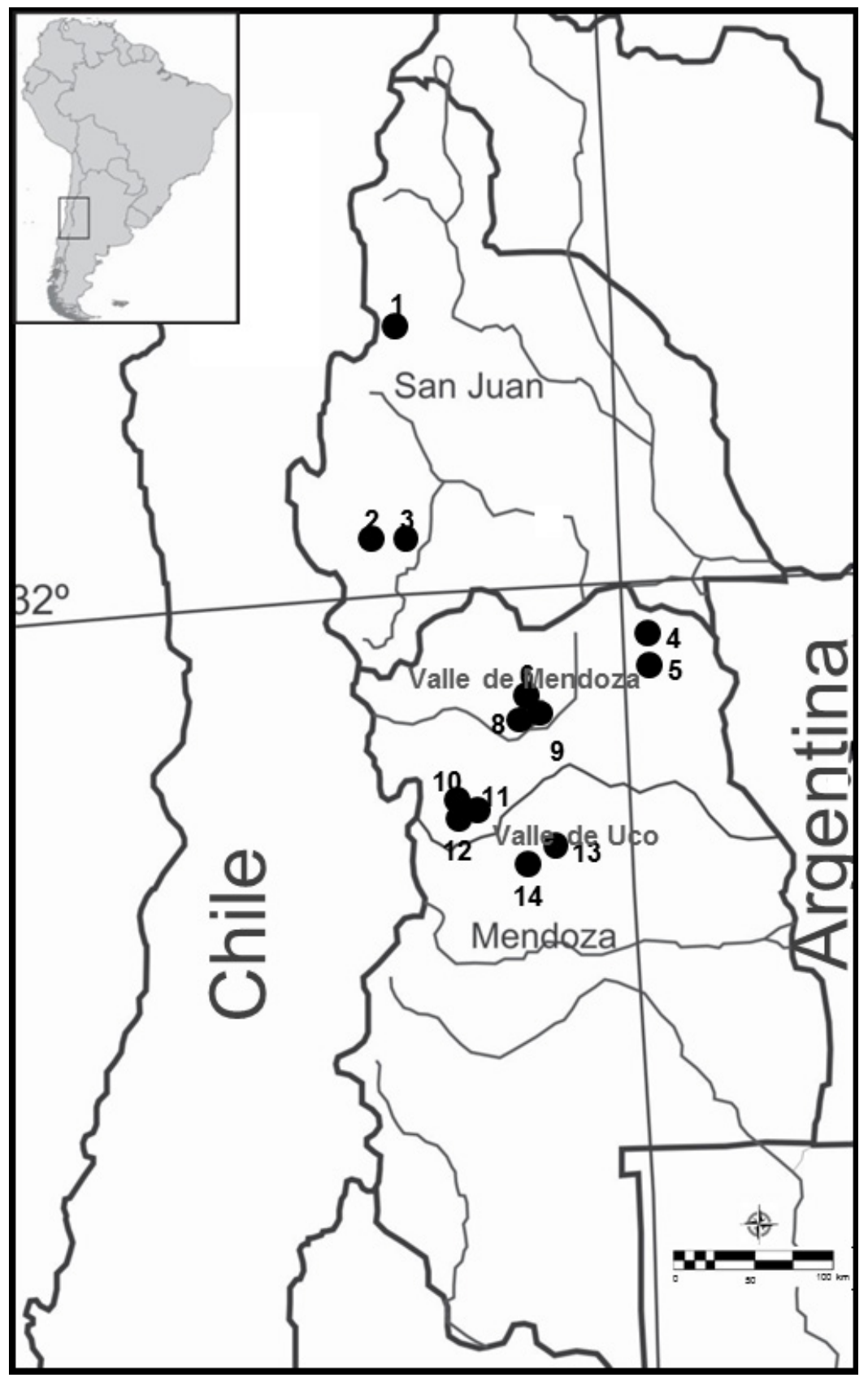

Figura 1. Mapa con las principales áreas mencionadas en el texto y la ubicación de los sitios arqueológicos de donde proceden las vasijas Viluco Inca Mixto analizadas (basado en la Figura 1 de Prieto Olavarría y Páez 2015). 1) Oeste de Iglesia (Iglesia); 2) Barrealito (Calingasta); 3) Valle de Calingasta (Calingasta); 4) El Algarrobito (Lavalle); 5) Estación Lagunas del Rosario (Lavalle); 6) Olascoaga (Las Heras); 7) Ruinas de San Francisco y Alberdi e Ituzaingó (Mendoza capital); 8) Tacuarí y 20 de junio, Beltrán y Liniers (Godoy Cruz); 9) Barrancas (Maipú); 10) Agua Amarga (Tunuyán); 11) Las Pintadas (Tunuyán); 12) La Arboleda II (Tupungato); 13) Cápiz I (San Carlos); 14) Viluco (San Carlos). 
piedemonte y planicie NE) (Prieto Olavarría 2012), donde se encontraban los principales núcleos de asentamiento indígena (Michieli 1983; Prieto 2000 [1983]). Además, con base en la evidencia alfarera recuperada en los sitios del valle de Mendoza, recientemente se definió la existencia de otro tipo, el Viluco Colonial (Prieto Olavarría et al. 2016). Desde esta perspectiva, las vasijas enteras y fragmentos recuperados de los contextos funerarios y domésticos, hacen del conjunto Viluco una de las evidencias más importantes de las interacciones entre las poblaciones locales y los dominadores en este sector del COA.

Los estudios etnohistóricos y arqueológicos indican que, en esta área, el ingreso inca y el español se produjeron en un lapso de aproximadamente 80 años, ya que la dominación incaica se materializó entre 1470/1480-1532/1536 DC (Bárcena y Román 1990), el primer ingreso español data de 1551 y la ciudad de Mendoza se fundó en 1561. Se propone que la dominación inca fue llevada a efecto por grupos de diverso origen trasladados hasta el COA, y que la mayor cantidad de evidencia corresponde a restos de cerámica Diaguita, la que habría sido ingresada por los mitmaqkuna de ese grupo procedente del Norte Chico chileno (Bárcena y Román 1990; Lagiglia 1978).

En estudios anteriores se consideró que algunas formas y decoraciones Viluco eran de origen incaico y que ciertos atributos fueron tomados de la cerámica Diaguita (Norte Chico chileno), Aconcagua (Chile central) y Angualasto (San Juan, Argentina) (Bárcena y Román 1990; García 1996; Lagiglia 1978), pero no se ha realizado un análisis exhaustivo sobre el origen de las formas, las decoraciones, ni de lo que pudo simbolizar este conjunto. Es por esto que en este trabajo proponemos analizar las formas y las decoraciones de la cerámica Viluco a la luz de los antecedentes de la cerámica Inca Cusqueña, de la Diaguita, de la producida en Chile central durante la dominación inca y de otros tipos producidos en el Área Andina Meridional. Un objetivo es explorar el origen de las formas y decoraciones Viluco, buscando aportar a la discusión de las tradiciones cerámicas que influyeron en su manufactura. También buscamos reflexionar sobre la dominación simbólica del Imperio inca en esta área periférica y lo que pudo representar la cerámica Viluco entre las poblaciones locales, tanto en tiempos incaicos como en los primeros años de la Colonia. Desde esta perspectiva, es necesa- rio comprender el significado de las vasijas en el marco del Tawantinsuyu, especialmente en el contexto de la dominación en el COA, por lo cual se aplica un marco interpretativo amplio y una metodología novedosa para esta área, la cual ha sido desarrollada para estudiar problemáticas etnohistóricas, etnográficas y arqueológicas (Bray 2003, 2004; Cummins 2002, 2007; González Carvajal 1998, 2008; González Carvajal y Bray 2008; Quispe-Agnoli 2005, 2008; Silverman 2011).

El análisis se basó en el relevamiento de todas las vasijas Viluco enteras recuperadas, tanto las depositadas en colecciones de museos de la provincia de Mendoza y que pudimos analizar directamente (Prieto Olavarría 2010a), como aquéllas a las que tuvimos acceso a través de imágenes publicadas (Lagiglia 1978; Rusconi 1962) o que fueron cedidas por sus autores. Esta estrategia de estudio implicó la revalorización, para fines de la investigación, de los materiales almacenados en colecciones. Con el objetivo de incluir más evidencia, consideramos fragmentos de gran tamaño recuperados en sitios domésticos del valle de Mendoza (Chiavazza 2005; Chiavazza et al. 2010; Prieto y Chiavazza 2009; Prieto Olavarría 2012). ${ }^{4}$

\section{$*$ Antecedentes}

\section{La cerámica en el Tawantinsuyu}

Las sociedades complejas como la inca necesitaron regular la comunicación y las interacciones entre los grupos que dominaron utilizando diversos soportes como el textil, la cerámica, el metal, la piedra y la arquitectura. Éstos fueron usados como medios para comunicar valores culturales y condicionar comportamientos e interrelaciones (Morris 1995). En el Tawantinsuyu, algunos objetos fueron poderosos comunicadores ligados a la difusión y la legitimación ideológica estatal, ya que la forma, la decoración y otros aspectos tecnológicos estuvieron cargados de significación (Hayashida 1994; Morris 1995; Rowe 1946). En palabras de Cummins, "the intimate physical interaction between image and object establishes an

4 Estudios detallados de la cerámica Viluco de contextos domésticos, y sus similitudes y diferencias con la cerámica de contextos funerarios están en Prieto Olavarría (2012) y Prieto y Chiavazza (2009). La metodología y los resultados del análisis de la decoración pintada se pueden consultar en Tobar (2013). 
expanded field of meanings that brings the image into the phenomenological sphere of social interaction and that brings the object into the sphere of the imaginary" (Cummins 2002: 2).

Existen diferentes opiniones sobre la relevancia que tuvo la cerámica dentro del conjunto de bienes que conformaron el repertorio estilístico. Algunos proponen un rol secundario comparado con la arquitectura, los metales y los textiles (Morris 1995) y otros postulan que tuvo una función relevante (Bray 2003; D’Altroy et al. 1994; Williams et al. 2005; Cummins 2002, 2007). En este sentido, hay que tener en cuenta que, en el marco de una economía estatal basada en el trabajo y una administración ejercida por medio del intercambio ritual, la hospitalidad y el reasentamiento de poblaciones, la cerámica fue un soporte que cumplió funciones relacionadas con la reciprocidad y las labores de administración (Cummins 2002; Williams et al. 2005).

La cerámica inca fue un importante medio de difusión ideológico, ya que se distribuyó ampliamente desde los centros productores a todo el Imperio, vinculándose a actividades relacionadas con los alimentos y la política. Más que un indicador del Estado, su importancia radicó en articular la producción, el consumo, la identidad y los procesos políticos del imperialismo inca (Bray 2003, 2004). Su carácter ceremonial y político se evidencia en que las formas más representadas se relacionan con el almacenamiento, el servicio de la comida (aríbalos, platos y pucos) (D'Altroy et al. 1994), la entrega de regalos y el brindis ritual (kero y aquillas) (Cummins 2002).

En las zonas periféricas del Estado, la cerámica incaica está escasamente representada, como sucede en los Andes meridionales, donde abundan otros tipos alfareros. Esto se debería a la menor importancia de los asentamientos, su distancia respecto de los centros de dominación y el menor control estatal (D’Altroy et al. 1994). Esta situación estimuló la circulación de otros tipos cerámicos (por ejemplo, Inca Pacajes y Yavi Chico Polícromo) (D'Altroy et al. 1994; Williams et al. 2005) y la producción de conjuntos locales que combinaron atributos incaicos y locales (Hayashida 1994; Morris 1995). Estas alfarerías regionales simbolizaron al Estado inca y fueron dispositivos de transmisión de la identidad étnica entre los grupos dominados (Hayashida 1994).

\section{$\underline{\text { La decoración como lenguaje visual }}$}

Se postula que los sistemas gráficos amerindios guardan y transmiten conocimientos o ideas combinando arte $y$ escritura, desafiando la división y el concepto moderno occidental de ambos (Boone y Mignolo 1994). Estos sistemas poseen lo que caracteriza a cualquier sistema de escritura: la permanencia, que incluye la recurrencia y continuidad de imágenes (Jackson 2008); la legibilidad, es decir, podían ser interpretados por sujetos distintos a sus creadores, ya que compartían una base cultural independientemente de la lengua (Boone 2000). En este sentido, se plantea que los códigos gráficos precolombinos son sistemas semasiográficos (Boone y Mignolo 1994), donde el significado es indicado por las interrelaciones de los símbolos codificados arbitrariamente y por las relaciones espaciales entre las partes. Son definidos como "their way of writing" (Boone y Mignolo 1994: 17) o "writing in images" (Boone 2000:3), aunque algunos investigadores prefieren hablar de grafismos amerindios (Salomon 2001) o de sistemas de comunicación visuales y tangibles (Quispe-Agnoli 2008).

Recientes investigaciones analizan los diversos mecanismos y tecnologías creadas para transmitir códigos de significación en el mundo andino, desarrollándose teorías y metodologías orientadas al estudio de las distintas expresiones materiales de los sistemas de comunicación visual (Boone y Mignolo 1994; Cummins 2002, 2007; Frame 2007; González Carvajal y Bray 2008; Martínez Cereceda 2008; Quispe-Agnoli 2005, 2008; Salomon 2001; Silverman 2011; Timberlake 2008, entre otros). En los Andes, los principales soportes a través de los cuales circularon códigos visuales fueron los textiles, la cerámica, las cuerdas, los nudos (khipu) y el arte rupestre (González Carvajal 2008). En éstos, las formas no figurativas fueron un sistema de notación en que la forma y el color eran los agentes de significación (Cummins 1993), por ejemplo, el tokhapu es un código gráfico andino de carácter geométrico y abstracto, plasmado en diversos soportes materiales incluida la cerámica (Cummins

\footnotetext{
5 Sistemas gráficos de comunicación donde las marcas comunican significado directamente y dentro de la estructura de su propio sistema, transmitiendo ideas independientemente del lenguaje y en el mismo nivel lógico que éste. Los grafismos amerindios son un tipo de sistema semasiográfico convencional (Boone y Mignolo 1994).
} 
2002; Frame 2007) y pinturas coloniales cusqueñas de los siglos XVI y XVII (Timberlake 2008).

La expansión y conformación del Imperio inca, entre los siglos XV y XVI, implicó el despliegue de un sistema de representación visual internamente coherente a lo largo de los Andes. Éste manifestaba los principios ordenadores del Tawantinsuyu, aunque es posible que más allá de lo que comunicaba (contenido semántico), el interés estaba en que fueran reconocidos visualmente como inca y distinguidos de las tradiciones locales (Cummins 2007). Junto con las estrategias militares, económicas (intensificación minera, agropastoril y artesanal), políticas y sociales (hospitalidad ceremonial, reubicación demográfica o movilización de poblaciones, tratamiento preferencial a ciertas etnias), los mecanismos de apropiación simbólica de los nuevos espacios conquistados, sirvieron para objetivar activamente situaciones de diferenciación y jerarquización en el marco de nuevas relaciones sociales creadas por la expansión del Imperio (Bray 2004; Williams 2008).

Los antecedentes más cercanos al COA sobre el estudio de los sistemas gráficos de comunicación, son los desarrollados con los diseños decorativos de la cerámica Diaguita Inca y cuyos resultados permitieron concluir que son parte de los lenguajes visuales incaicos (González Carvajal 1998, 2008). ${ }^{6}$ Estudios arqueológicos demuestran que las estructuras del diseño, antes que los motivos o unidades mínimas de éste, son más sensibles al cambio cultural (Washburn 1987). Esto se observa en la sucesión que se da entre la alfarería Diaguita Clásico y la Diaguita Inca, ya que, en esta última, la estructura simétrica de doble reflexión especular produce una resignificación y transformación de los motivos locales, logrando la imposición simbólica del principio de cuatripartición a partir del ingreso incaico en el Norte Chico chileno (González Carvajal 1998, 2008).

Estas investigaciones son relevantes para los objetivos de este trabajo, ya que grupos de mitmaqkuna diaguita habrían cumplido una importante función en el proceso de dominación del COA. El trabajo de González

6 La secuencia cronológica relativa de la cultura Diaguita: Diaguita I o Transición entre el 1000 y el 1200; Diaguita II o Clásico entre el 1220 y 1470; Diaguita III o Diaguita Incaico entre 1470 y 1537 (Ampuero 1986).
Carvajal (1998, 2004a, 2004b, 2008, 2013) combina el enfoque de los sistemas de comunicación visual con el análisis de las estructuras simétricas e interpreta los principios simétricos articulando el análisis del diseño con información etnohistórica, etnográfica y el análisis de los contextos arqueológicos (González Carvajal 1998, 2008, 2013). En este trabajo desarrollamos esta línea de investigación para analizar las combinaciones recurrentes de los elementos y las estructuras subyacentes de la decoración pintada, ya que los sistemas incaicos de representación gráfica no son figurativos y para estudiar su significado es necesario analizar las interrelaciones y ordenamientos espaciales de estos símbolos (González Carvajal y Bray 2008).

\section{La dominación inca y la cultura Viluco}

El sur de la provincia de San Juan y el norte y centro de la provincia de Mendoza constituyeron el extremo suroriental del Tawantinsuyu (Bárcena 2002; Lagiglia 1978). En este contexto, el valle de Uco (centro de Mendoza), fue la frontera meridional oriental que tuvieron incas y españoles con las poblaciones no sometidas del sur ( $\mathrm{La}$ giglia 1980). El carácter meridional del sector influyó en que la dominación inca fuera tardía y estuviera en proceso de consolidación cuando se produjo la llegada de los españoles. El interés en este sector habría sido funcional a la conquista de los valles centrales y Norte Chico de Chile; por ello los enclaves incaicos en el COA habrían sido avanzadas hacia la periferia de una división geográfico-administrativa mayor que tuvo su núcleo en el área chilena (Bárcena 2002; Bárcena y Román 1990). Se planteó un modelo de dominación en el cual los tambos y la red vial ubicada en los valles interandinos de Uspallata y Calingasta (1900-2500 msnm), configuraron un límite que incluyó: una situación interna al occidente, que tenía como objetivo consolidar esta área y asegurar la comunicación con los valles centrales de Chile; una situación externa hacia el oriente, sector de tierras bajas (1500-300 $\mathrm{msnm}$ ), periféricas y de transición, en la que se establecieron enclaves en la llanura y en los valles del piedemonte de San Juan, Mendoza y Uco (Bárcena 2002; Cahiza y Ots 2005). Los enclaves funcionaron como frontera económica productiva y estructurada en una territorialidad discontinua de archipiélagos, lo que habría implicado que en los valles se intensificara la producción agrícola, el sedentarismo y se concentrara población local huarpe y 
mitmaqkuna, configurándose espacios dinámicos de interacción étnica y cultural (Cahiza y Ots 2005).

En esta área, se desarrolló la cultura Viluco entre los siglos XV y XVII, la cual fue definida por Lagiglia (1978) y es considerada la evidencia material de la etnia Huarpe (Bárcena 2002; Boman 1920; Canals Frau 1946; Cahiza y Ots 2005; García 1996; Lagiglia 1978; Prieto Olavarría 2012). Aunque tradicionalmente se postuló que Viluco se desenvolvió desde tiempos preincaicos hasta la Colonia (Lagiglia 1978), actualmente hay acuerdo en que su origen fue consecuencia del ingreso inca y perduró hasta el siglo XVII (García 1996; Prieto Olavarría 2012; Prieto Olavarría y Chiavazza 2010, 2015). Esto se manifiesta claramente en la presencia de cerámica Viluco en contextos funerarios y domésticos que abarcan ese lapso (Chiavazza 2005, 2010; Lagiglia 1978; Novellino et al. 2003; Prieto y Chiavazza 2009; Prieto Olavarría 2012).

\section{La cerámica Viluco}

La dominación inca en Mendoza y San Juan repercutió en las poblaciones locales, produciendo profundos cambios sociales, políticos y culturales (Bárcena 2002). Aunque se menciona una continuidad entre las poblaciones locales más tempranas y las tardías (Canals Frau 1956; García 2007), hasta el momento no ha sido posible establecer una relación entre la cultura Viluco y la de Agrelo que caracteriza al período anterior en el COA (Alfarero Medio, ca. 1600-600 AP) (Bárcena 2002).

En un primer momento se propuso que el origen y desarrollo de Viluco estuvo marcado por diversas influencias debido a su pertenencia al Área Andina Meridional, las que habrían ingresado al COA desde Chile central (Lagiglia 1978). Concretamente, el origen de la cerámica Aconcagua (Chile central) y Viluco se habría dado a partir del influjo de la tradición alfarera andina meridional proveniente de la puna de Atacama, la cual, influenciada por el Tiwanaku Expansivo, se expresó en los tipos inspirados en las del Período Medio y Tardío de Arica (norte de Chile): Maytas, San Miguel y Gentilar (Lagiglia 1978). Se identificó que las principales formas respondían a los parámetros de la alfarería incaica, tal como las escudillas con apéndices ornitomorfos, los aríbalos y la jarra con asa transversal, mientras que los kero tenían similitudes con la cerámica de Tiwanaku (Lagiglia 1978). Estudios posteriores postularon que los alfareros huarpe asimilaron y reelaboraron atributos decorativos y morfológicos provenientes de la cerámica Diaguita (Norte Chico chileno), Aconcagua (Chile central), Angualasto (San Juan, Argentina) e Inca, como consecuencia del traslado de mitmaqkuna y artesanos especialistas de diversos orígenes (García 1996). Hace algunos años se compararon las pastas Viluco con la de los tipos cerámicos producidos en los tambos de Uspallata (Anaranjado sin pintura roja y Anaranjado pintado de rojo), y se definió que ambos pertenecen a la misma tradición tecnológica (Ots 2008).

Actualmente existe un registro más completo de las vasijas Viluco debido al desarrollo de las investigaciones de los contextos domésticos hallados en el valle de Mendoza (Área Fundacional). A las formas ya conocidas, se sumaron las escudillas sin apéndices (Prieto Olavarría 2012), los platos Viluco (Prieto y Chiavazza 2009) y las ollas usadas para cocinar (Castillo 2013). Además, el estudio de las pastas indicó que no solo se incorporaron formas y decoraciones asociadas a la expansión inca, sino que algunas vasijas Viluco fueron confeccionadas con pastas con altos porcentajes de inclusiones piroclásticas (pómez y trizas vítreas), práctica que ingresó al área junto con la dominación incaica (Prieto Olavarría 2012; Prieto Olavarría et al. 2010; Prieto Olavarría y Castro de Machuca 2015; Prieto Olavarría y Páez 2015). Estas pastas se relacionan con vasijas cerámicas que circularon como bienes de prestigio entre las poblaciones locales (Cremonte 1994; Cremonte et al. 2007), y fueron importantes en las estrategias de dominación en las áreas meridionales y fronterizas del Imperio como el COA y Tafí del Valle en el NOA (Páez y Arnosio 2009; Prieto Olavarría 2012; Prieto Olavarría y Páez 2015).

Por su parte, los platos Viluco integran el tipo Viluco Colonial (Prieto Olavarría et al. 2016), ya que evidencian la confluencia de atributos Viluco (pastas y decoración pintada) y de tradición europea (forma de plato similar a los de mayólica y uso del torno) (Prieto Olavarría 2012; Prieto y Chiavazza 2009; Prieto Olavarría y Castro de Machuca 2015). Estas formas están representadas casi exclusivamente en los contextos domésticos del primer siglo de la Colonia en el Área Fundacional de Mendoza (Prieto y Chiavazza 2009; Prieto Olavarría 2013). 
Sobre la base de los estudios petrográficos, se propuso que la cerámica Viluco (Inca Mixto y Colonial) fue producida con materias primas locales (Prieto Olavarría 2012, Prieto Olavarría y Castro de Machuca 2015), lo que se ratificó con el análisis petrográfico comparativo con las materias primas locales (Prieto Olavarría y Castro de Machuca 2017). Por su parte, los antecedentes, la evidencia contextual y los resultados morfométricos de la cerámica recuperada en el valle de Mendoza, permitieron inferir que este conjunto fue producido de manera descentralizada y a pequeña escala, probablemente a nivel familiar (Prieto Olavarría 2012). En el caso de las vasijas producidas en los enclaves incaicos y tambos de Mendoza, habrían sido manufacturadas de forma centralizada, posiblemente bajo el control de funcionarios incaicos, como parte de la estrategia que tuvo como objetivo organizar las actividades relevantes para la distribución y redistribución en el sistema imperial (Bárcena y Román 1990; Prieto y Chiavazza 2009).

La variabilidad de la cerámica Viluco, la organización de su producción, la tecnología, el uso y la función, condujeron a reflexionar sobre el rol activo que tuvo en las relaciones sostenidas entre los dominados (indígenas locales) y los dominadores (incas y españoles) (Prieto Olavarría 2012), y en la construcción de nuevas identidades y el proceso de etnogénesis de los grupos huarpe durante el primer siglo de la Colonia (Prieto Olavarría 2o1ob; Prieto Olavarría y Chiavazza 2015). Esta cerámica, surgida y desarrollada bajo presiones sociales, políticas, económicas y simbólicas, es un conjunto politético (en el sentido de Gosselain 1998), cuyos diferentes componentes no reflejaron los mismos aspectos culturales, ya que éstos surgieron de procesos relacionados con el contacto entre diversas poblaciones y los cambios en los contextos de producción y consumo de las vasijas. Los atributos inspirados en la alfarería incaica están asociados a la legalidad y al estatus imperial, por lo cual el uso de cerámica Viluco como ofrenda funeraria y para el servicio y consumo de alimentos se relacionó con una función activa, ya que cumplió el rol de mediador visual en los procesos sociales y políticos durante el dominio inca y los primeros años de la Colonia, tanto en los espacios de frontera del valle de Uco como en la naciente ciudad de Mendoza (Prieto Olavarría 2013). Desde esta perspectiva, se le considera un dispositivo simbólico (Prieto Olavarría 2012), en el contexto de la reorganización de las estructuras de autoridad tradicional y los sistemas de prestigio social que se desarrollaron dentro de las jefaturas huarpe (Michieli 1983; Prieto 2000 [1983]), ya que estas jefaturas locales huarpe estaban en un profundo proceso de desestructuración social y política en la cual algunos caciques mantuvieron relaciones de privilegio con los grupos dominantes, lo que se evidenció en el acceso diferencial a los bienes productivos (tierras irrigadas y aptas para el cultivo) y en la administración del trabajo de quienes se mantenían bajo su cacicazgo (Parisii 1994).

\section{Materiales y método}

Se analizaron las formas y decoraciones de 59 piezas Viluco Inca Mixto: 54 vasijas enteras y cinco fragmentos. Las enteras corresponden a todas las vasijas a las que tuvimos acceso en los museos provinciales y a las que están publicadas con imágenes (dibujos y fotos), por lo cual consideramos que es el análisis más completo de vasijas Viluco realizado. También se incluyeron fragmentos de grandes dimensiones, procedentes de contextos domésticos, que podían ser analizados en su decoración.

Las vasijas enteras (algunas restauradas o ensambladas) fueron recuperadas mayoritariamente de contextos funerarios del período incaico y de contacto hispano-indígena del norte y centro de la provincia de Mendoza, y de la provincia de San Juan (Tabla 1 y Tabla 2). La procedencia de las vasijas de San Juan no es clara, por lo cual en la Tabla 2 se indican entre signos de interrogación. Las dos jarras y el vaso de Calingasta (Tabla 2) que pertenecen a la colección Aguiar, están depositados en el Museo de La Plata y no cuentan con datos claros de procedencia debido a la escasa información aportada por el coleccionista. Debenedetti (1917) notó esta falencia, aunque siguió sosteniendo que las vasijas procedían de aquella zona. Por su parte, Michieli (1998) discutió los problemas sobre su origen e indicó que posiblemente procedían de la zona de Lagunas de Guanacache (ubicadas en el límite sur de San Juan y norte de Mendoza), donde Aguiar tenía grandes extensiones de tierra. Lo mismo sucedió con las jarras del

7 No se incluyeron los platos, ya que corresponden al tipo Viluco Colonial. Un trabajo comparativo entre ambos tipos se presentó en el simposio "Perspectivas analíticas y de conservación de materiales cerámicos y vítreos en contextos posthispánicos. Discusión y resultados", VI Congreso Nacional de Arqueología Histórica Argentina, Mendoza, 2015. 
departamento de Iglesia recuperadas por A. R. González en el valle interprecordillerano de Gualilán y que fueron relocalizadas como provenientes del sudoeste del valle de Iglesia (Michieli 1998).

Se trabajó con dos metodologías de análisis de acuerdo a la posibilidad de acceso a estas piezas. La mayoría $(n=39)$ fueron estudiadas directamente, ya que se accedió a las colecciones depositadas en museos públicos de la provincia de Mendoza (Prieto Olavarría 2010a). Se registraron individualmente los atributos morfométricos, de decoración y huellas de uso. Cada pieza fue fotografiada, y los dibujos de los perfiles y las decoraciones (escala 1:1) se digitalizaron (Rice 1987). En aquellos casos $(n=15)$ en que no tuvimos acceso a las vasijas, porque no se pudo acceder a ellas en los museos locales o estaban en instituciones de otras provincias o extranjeras, el relevamiento de las decoraciones pintadas y modeladas se realizó a partir de los dibujos publicados y fotografías de archivo (Tobar 2013). El criterio de selección de estas imágenes se basó en la posibilidad de identificar en el campo del diseño la unidad mínima decorativa que se repetía por alguno de los movimientos simétricos siguiendo la propuesta de Washburn y Crowe (1988). Complementariamente, se incluyeron cinco fragmentos de gran tamaño procedentes de los contextos domésticos del valle de Mendoza (Área Fundacional) ( $n=5$ ) (Tabla 1) y la metodología utilizada se adaptó de la desarrollada para las vasijas enteras. La identificación de las estructuras del diseño en muestras fragmentarias está sujeta metodológicamente a la posibilidad de identificar la unidad mínima, dado que la simetría no describe las partes sino cómo éstas son combinadas y articuladas para hacer un patrón (Washburn y Crowe 1988). En este caso, se seleccionaron: tres partes de piezas ensambladas que forman la mitad de la vasija original; dos apéndices que representan cabezas de camélido y que son decoraciones modeladas únicas registradas en Viluco.

Los análisis se realizaron a partir de la comparación de los atributos morfológicos y decorativos de la cerámica Viluco con los antecedentes existentes para la alfarería Inca Cusqueña (Bingham 1930; Fernández Baca 1971; Meyers 1975) y la Diaguita del Norte Chico chileno (Cantarutti 2002; Cantarutti Rebolledo y Mera Moreno 2004; González Carvajal 1998, 2008). Exploratoriamente se analizó la información de la alfarería Angualasto y otros tipos hallados en la cordillera de la provincia de San Juan (Michieli 1998, 2015); de la cerámica Agrelo de Mendoza (Canals Frau 1956; Canals Frau y Semper 1956; Michieli 1974); de la cerámica de Chile central del Período Tardío (incaico) (Cantarutti y Mera 2002); de diversos tipos de la cerámica de Arica (Uribe 1998).

Con el objetivo de unificar los criterios clasificatorios de las vasijas, se usaron las categorías morfológicas definidas por Meyers (1975) para la cerámica Inca Cusqueña, ya que su clasificación fue diseñada para facilitar la comparación con la alfarería provincial. Complementariamente, la descripción morfológica se hizo con base en el sistema general de clasificación de formas de Shepard (1956).

La comparación de las tendencias de representación de las diferentes formas cerámicas Viluco en el COA con las del resto del incario, se realizó a partir del análisis distribucional de las vasijas incaicas del Imperio (Bray 2003, 2004), lo que permitió tener una visión general de la representación y relevancia de las diferentes formas del equipo culinario en las provincias.

El estudio de la decoración pintada se abordó a partir del análisis de simetría (Washburn 1987; Washburn y Crowe 1988), ya que para decodificar un sistema semasiográfico es necesario comprender los principios estructurales que lo gobiernan o la gramática que le da orden al sistema y permite interpretar una imagen (González Carvajal y Bray 2008). La simetría es una unidad analítica objetiva que puede usarse en la descripción de la gramática de los sistemas artísticos (Washburn 1983), por lo tanto, es un método apropiado para el estudio de las regularidades encontradas en la cultura material, porque expresa patrones del comportamiento humano y subyace al estilo, implicando elecciones vinculadas a la identidad de un grupo social y a la interacción grupal (Washburn y Crowe 1988). Este análisis se basa en la superposición de elementos, los que se intercalan regularmente a lo largo y/o alrededor de un eje o en torno a un punto axial, son regularmente repetidos y el patrón resultante es simétrico. De este modo, en la estructura del diseño existe una unidad mínima o motivo, que se repite sobre sí misma por alguno de los movimientos simétricos generando el patrón (Washburn y Crowe 1988). Los movimientos simétricos son cuatro: traslación, reflexión especular, reflexión desplazada y 


\begin{tabular}{|c|c|c|c|c|c|}
\hline Valle & Departamento & Sitio & Contexto & $\begin{array}{l}\text { Categoría morfológica e } \\
\text { identificación }\end{array}$ & Referencias \\
\hline \multirow{10}{*}{$\begin{array}{l}\text { Valle de } \\
\text { Uco } \\
\text { Centro de } \\
\text { Mendoza }\end{array}$} & \multirow[t]{2}{*}{ Tunuyán } & Agua Amarga & $\begin{array}{l}\text { Contexto funerario } \\
\text { indígena colonial }\end{array}$ & $\begin{array}{c}\text { Jarras gemelas } 1218 \text { y } 10331 \\
\text { Jarras } 10333,10334 . \\
\text { Vasos gemelos } 10329,10332 \\
\text { Vaso con asa } 10330 \\
\text { Escudillas gemelas } 1219,10335 \\
\text { Escudilla } 10336 \\
\text { Botella con cuello corto } 10347 \\
\text { Aríbalo } 10348\end{array}$ & $\begin{array}{c}\text { Lagiglia } 1978 \\
\text { Prieto Olavarría 2010a, 2012; } \\
\text { Prieto y Chiavazza } 2009\end{array}$ \\
\hline & & Las Pintadas & Contexto Funerario* & Jarra 18 & $\begin{array}{c}\text { Rusconi 1962, Figura } 127 \\
\text { Lagiglia 1978: 236, Lámina XXVIII }\end{array}$ \\
\hline & \multirow[t]{7}{*}{ San Carlos } & \multirow[t]{6}{*}{ Viluco } & \multirow[t]{6}{*}{$\begin{array}{l}\text { Contexto funerario } \\
\text { indígena colonial }\end{array}$} & $\begin{array}{c}\text { Jarras 204, 346, 205, } 198 \\
\text { Vasos 201, 208, } 248 \\
\text { Vasos con asa } 206 \\
\text { Escudillas 199, } 211\end{array}$ & $\begin{array}{c}\text { Lagiglia } 1978 \\
\text { Prieto Olavarría } 2010 a\end{array}$ \\
\hline & & & & Jarras 13 y 14 & Lagiglia 1978: 237, Lámina XXVIII. \\
\hline & & & & Vaso Fig. 4 & Lagiglia 1978: 233 \\
\hline & & & & Vaso 253 & $\begin{array}{c}\text { Rusconi 1962: } 72 \\
\text { Lagiglia 1978, Lámina XXVI }\end{array}$ \\
\hline & & & & Vaso 7 & $\begin{array}{c}\text { Rusconi 1962: } 76 \\
\text { Lagiglia 1978, Lámina XXVI }\end{array}$ \\
\hline & & & & Vaso 20723 & $\begin{array}{c}\text { Lagiglia 1978: 232, Lámina XXVI, } \\
\text { Figura } 12\end{array}$ \\
\hline & & Capiz I & $\begin{array}{l}\text { Contexto funerario } \\
\text { indígena colonial }\end{array}$ & $\begin{array}{c}\text { Jarra E16 } \\
\text { Vaso E15 } \\
\text { Escudilla E16-1 }\end{array}$ & $\begin{array}{l}\text { Novellino et al. } 2003 . \\
\text { Prieto Olavarría } 2010 a\end{array}$ \\
\hline & Tupungato & La Arboleda II & $\begin{array}{c}\text { Hallado en superficie } \\
\text { asociado a fragmentos de } \\
\text { cerámica inca }\end{array}$ & Jarra $79 / 12$ & $\begin{array}{l}\text { Canals Frau 1950: } 24-25 \\
\text { Prieto Olavarría 2010a }\end{array}$ \\
\hline \multirow{10}{*}{$\begin{array}{l}\text { Valle de } \\
\text { Mendoza }\end{array}$} & \multirow[t]{3}{*}{ Maipú } & \multirow[t]{3}{*}{ Barrancas } & $\begin{array}{l}\text { Contexto funerario } \\
\text { indígena colonial }\end{array}$ & $\begin{array}{c}\text { Jarras } 3993,3994,1217^{\star} \\
\text { Vaso } 8076 \text { (ver Lagiglia 2000) } \\
\text { Escudilla } 8077\end{array}$ & $\begin{array}{c}\text { Canals Frau } 1946 \\
\text { Prieto Olavarría 2010a } \\
\text { Rusconi } 1964 \\
\end{array}$ \\
\hline & & & Sin información contextual & Jarra 16 & $\begin{array}{l}\text { Colección privada de Canals Frau } \\
\text { 1950: 81-82 } \\
\text { Lagiglia 1978: 236, Lámina XXVIII }\end{array}$ \\
\hline & & & Sin información contextual & Jarra MAF119-120* & $\begin{array}{l}\text { Colección privada de Humberto } \\
\text { Giannaccari. } \\
\text { Fotografía del repositorio del Museo } \\
\text { del Área Fundacional. }\end{array}$ \\
\hline & \multirow[t]{2}{*}{ Godoy Cruz } & $\begin{array}{l}\text { Tacuarí y zo de } \\
\text { Junio }\end{array}$ & Contexto Funerario* & Jarra 3991, 3910, 3911, 3912 & $\begin{array}{c}\text { Prieto Olavarría 2010a } \\
\text { Rusconi 1956, } 1962 \\
\end{array}$ \\
\hline & & Beltrán y Liniers & Sin información contextual & Jarra $1216^{*}$ & Prieto Olavarría zoloa \\
\hline & Las Heras & Olascoaga & Contexto Funerario* & Aríbalo 4024 & $\begin{array}{c}\text { Rusconi } 1967 \\
\text { Prieto Olavarría } 2010 a\end{array}$ \\
\hline & \multirow[t]{2}{*}{ Lavalle } & El Algarrobito & Sin información contextual & Jarra $1215^{*}$ & Prieto Olavarría 2010a \\
\hline & & $\begin{array}{c}\text { Estación Lagunas } \\
\text { del Rosario }\end{array}$ & Sin información contextual & Jarra 1604 & $\begin{array}{c}\text { Rusconi 1962, } \\
\text { Lagiglia 1978, Figura } 8\end{array}$ \\
\hline & Mendoza Capital & $\begin{array}{l}\text { Ruinas de San } \\
\text { Francisco }\end{array}$ & $\begin{array}{l}\text { Contexto doméstico } \\
\text { indígena colonial }\end{array}$ & $\begin{array}{c}\text { Fragmento de jarra } 9828 \\
\text { Fragmentos de escudilla 13273- } \\
13277 \\
\end{array}$ & $\begin{array}{c}\text { Prieto Olavarría y Chiavazza 2010; } \\
\text { Prieto Olavarría } 2012\end{array}$ \\
\hline & Mendoza Capital & $\begin{array}{l}\text { Alberdi e } \\
\text { Ituzaingó }\end{array}$ & $\begin{array}{l}\text { Contexto doméstico } \\
\text { indígena colonial }\end{array}$ & $\begin{array}{l}\text { Fragmento de escudilla } 778 \\
\text { Fragmento de escudilla } 1160 \\
\text { Fragmento de olla con pie } 766\end{array}$ & Prieto Olavarría 2012, 2013. \\
\hline
\end{tabular}

Tabla 1. Vasijas y fragmentos Viluco Inca Mixto analizados de la provincia de Mendoza.

*Vasijas encontradas en contextos funerarios de los que no hay información contextual. 


\begin{tabular}{|c|c|c|c|c|}
\hline Departamento & Localidad & Contexto & $\begin{array}{c}\text { Categoría morfológica e } \\
\text { identificación }\end{array}$ & Referencias \\
\hline ¿Iglesia? & ¿Oeste de Iglesia? & $\begin{array}{c}\text { Sin información } \\
\text { contextual }\end{array}$ & Jarra 10 y 11 & $\begin{array}{c}\text { Debenedetti 1917 } \\
\text { Lagiglia 1978: 236-237, Lámina XXVII }\end{array}$ \\
\hline \multirow{2}{*}{ ¿Calingasta? } & iValle de Calingasta? & $\begin{array}{c}\text { Sin información } \\
\text { contextual }\end{array}$ & Jarra 6625 y 6621 & $\begin{array}{c}\text { Debenedetti 1917 } \\
\text { Lagiglia 1978: 233, Lámina XXVIII, Figura 17 } \\
\text { y 19 }\end{array}$ \\
\cline { 2 - 5 } & ¿Barrealito? & $\begin{array}{c}\text { Contexto funerario con } \\
\text { evidencia incaica }\end{array}$ & Vaso 11BARR & Debenedetti 1917 \\
& & &
\end{tabular}

Tabla 2. Vasijas y fragmentos Viluco Inca Mixto analizados de la provincia de San Juan. ${ }^{8}$

rotación (Washburn y Crowe 1988); y son las reglas que configuran el diseño gráfico como en un lenguaje gramático (Tobar 2013). La traslación es la base del patrón de un diseño decorativo e implica que la unidad mínima se traslada a lo largo de un eje superponiéndose sobre sí misma de manera regular, extendiéndose conceptualmente al infinito. El patrón infinito en textiles y vasijas es cuando hay suficientes repeticiones de la unidad mínima que parece extenderse para llenar una banda infinita o el plano completo (Washburn y Crowe 1988). Hay tres categorías de patrones en los diseños planos: a) diseño finito: presenta un punto central axial alrededor del cual los elementos pueden rotar (rotación) o posee ejes de reflexión (vertical/horizontal) a través de los que se superponen los elementos. En este diseño no hay traslación o reflexión desplazada, por ello no es un patrón en sentido estricto, ya que un patrón es un diseño que posee traslación; b) patrón unidimensional: cuando un diseño admite traslación en una dirección. La regla general es que un patrón unidimensional debe tener al menos la unidad mínima y una copia de ella por traslación. Rotación o reflexión no son suficientes; c) patrón bidimensional: cuando admite traslaciones en dos o más direcciones, la intersección de dos ejes supone un centro de rotación. La regla es que debe tener al menos la unidad mínima, una copia por traslación, y una copia de ellos dos por traslación en una segunda dirección (Washburn y Crowe 1988).

8 El problema sobre la procedencia (indicada en la Tabla 2 entre signos de interrogación) de estas vasijas se menciona en el primer párrafo de este apartado (ver Debenedetti (1917) y Michieli (1998)).

\section{* Resultados}

\section{Análisis de las formas}

A partir del análisis comparativo de las vasijas Viluco con los antecedentes, identificamos morfologías inspiradas en la cerámica Inca Cusqueña (Tabla 3). En el listado que sigue, caracterizamos las formas usando denominaciones generales y locales: primero, se identifican con las categorías propuestas por Meyers (1975); luego, y entre paréntesis, se indica la denominación local utilizada por Lagiglia (1978); finalmente, cada forma se describe según las categorías propuestas por Shepard (1956) (Figura 2):

a. Cántaro o aríbalo (aribaloide). Las dos vasijas de esta categoría son diferentes: la 4024, es restringi$\mathrm{da}$ con cuello de contorno inflectado, tiene dos asas opuestas adheridas a la parte media del cuerpo; la 10348, es restringida con cuello de contorno complejo y tiene un asa de faja vertical con inserción labio/sector superior del cuerpo (Figura 2A).

b. Botella con cuello corto (jarra con asa transversal). Presenta un asa transversal en el sector superior del cuerpo y es una vasija restringida con cuello de contorno complejo (Figura 2B).

c. Vaso (kero). Vasijas no restringidas de contornos simples de forma hiperboloide (Figura 2C). Los kero 10332 y 206 tienen un asa oval adherida labio/sector inferior del cuerpo (Figura 2D).

d. Olla con pie. Solo se cuenta con el fragmento del pie 766. Si se considera la morfología completa (Meyers 1975), es una vasija restringida de contorno complejo (Figura $2 \mathrm{E}$ ). 


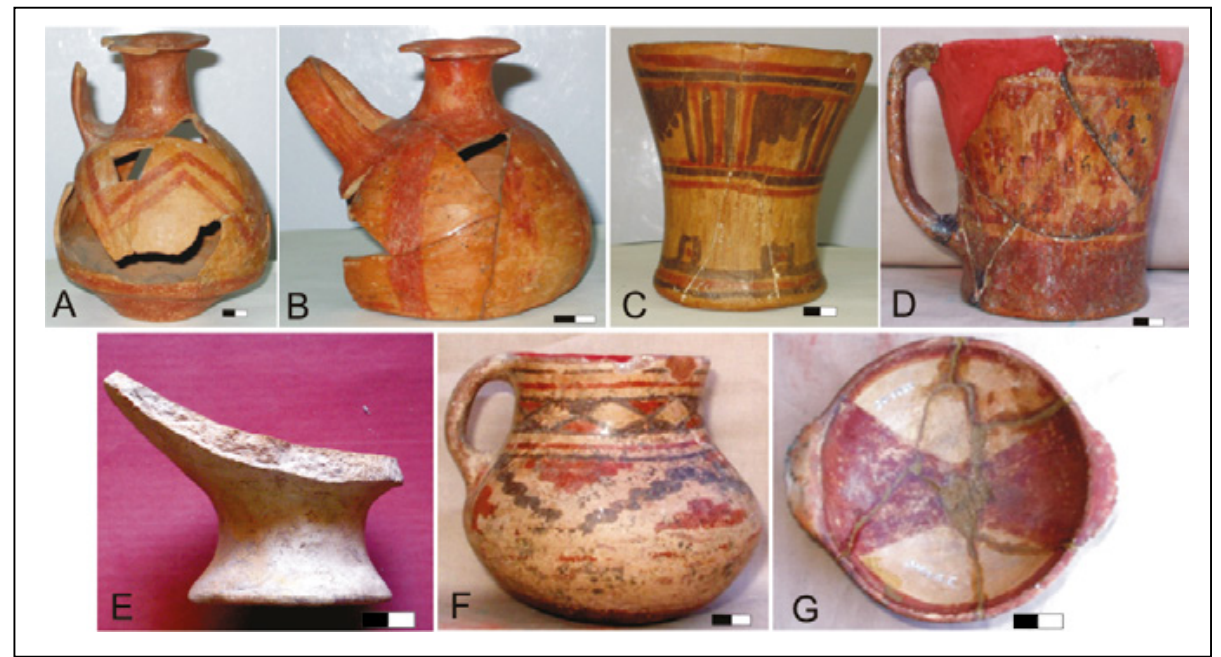

Figura 2. Vasijas que representan las categorías morfológicas de la cerámica Viluco Inca Mixto. A) cántaro o aríbalo 10348 (cementerio de Agua Amarga); B) botella de cuello corto 10347 (cementerio de Agua Amarga); C) vaso 10332 (cementerio de Agua Amarga); D) vaso con asa 206 (cementerio de Viluco); E) olla con pie 766 (sitio doméstico Alberdi e Ituzaingó); F) jarra 3991 (contexto funerario de Tacuarí y 20 de Junio); G) escudilla 3993 (contexto funerario de Tacuarí y 20 de Junio).

Estas vasijas Viluco no imitan exactamente las piezas cusqueñas, por lo cual proponemos que los artesanos locales reinterpretaron las formas que habrían ingresado al área con los grupos mitmaqkuna. Hay que destacar que la forma del aríbalo 4024, la botella con cuello corto y la olla con pie, son formas que están presentes en la cerámica Diaguita Inca y en Chile central de Fase Inca.

Por su parte, las escudillas y las jarras Viluco no se corresponden con las formas de inspiración imperial, pero sí son semejantes a formas cerámicas de Chile central y del Norte Chico (Tabla 3). Las escudillas Viluco con decoraciones modeladas son vasijas no restringidas de contornos simples, con una razón diámetro máximo y altura igual a 2 o levemente mayor (Figura 2G) (Prieto Olavarría 2012); las jarras Viluco son vasijas restringidas con cuello de contorno inflectado, con un asa oval adherida labio/sector superior del cuerpo (Figura 2F). Aunque estas formas están representadas en la cerámica cusqueña, observamos diferencias que no permiten hacer un paralelo: las escudillas Viluco son altas (alturas entre 5,1 y $8,4 \mathrm{~cm}$ ) y tienen bases convexas (Prieto y Chiavazza 2009), mientras que las escudillas incaicas se caracterizan por tener bases planas y son bajas (aproximadamente $3 \mathrm{~cm}$ de altura) (Meyers 1975). En el caso de las jarras, las Viluco son pequeñas (alturas entre 10 y $14 \mathrm{~cm}$ ), de formas globulares, tienen bases convexas y el asa siempre conecta con el labio, mientras que los jarros incaicos tienen cuerpos alargados o globulosos, cuellos estrechos, labios expandidos, bases planas, un asa de faja que conecta el sector superior del cuerpo con el labio o el borde y son altas (alturas entre 15 y $25 \mathrm{~cm}$ ) (Meyers 1975).

El análisis comparativo con las piezas chilenas muestra que las escudillas y las jarras Viluco tienen atributos morfológicos similares a la categoría Diaguita Patrón Local (Fase Inca), las que a su vez tendrían su origen en la alfarería Diaguita producida antes de la dominación incaica (Cantarutti 2002; Cantarutti Rebolledo y Mera Moreno 2004). Las formas de las escudillas Viluco también fueron populares en la cerámica Aconcagua (Chile central) anterior a la dominación incaica, y continuaron produciéndose en el Período Aconcagua de Fase Inca (escudillas rojo engobado) (Cantarutti y Mera 2002).

La ausencia de información métrica detallada de todas estas formas mencionadas no permite hacer una comparación sistemática de las medidas, pero preliminarmente hacemos un análisis comparativo con las medidas publicadas (Tabla 4 y Tabla 5) (Cantarutti y Mera 2002; Meyers 1975; Prieto y Chiavazza 2009) 


\begin{tabular}{|c|c|c|c|c|c|c|c|}
\hline \multirow[t]{2}{*}{ Sitio o Localidad } & \multicolumn{2}{|c|}{$\begin{array}{l}\text { Formas con influencia } \\
\text { de Chile central y Norte } \\
\text { Chico chileno }\end{array}$} & \multicolumn{4}{|c|}{ Formas con influencia Inca Cuzqueña } & \multirow{2}{*}{$\begin{array}{c}\text { N Total vasijas } \\
\text { por sitio }\end{array}$} \\
\hline & N Jarra & $\begin{array}{c}\mathbf{N} \\
\text { Escudilla }\end{array}$ & N Vaso (kero) & $\begin{array}{c}\text { N Botella } \\
\text { cuello corto } \\
\text { (jarra con asa } \\
\text { transversal) }\end{array}$ & $\begin{array}{c}\text { N Cántaro } \\
\text { (aríbalo) }\end{array}$ & N Olla con pie & \\
\hline Agua Amarga & 4 & 3 & 3 & 1 & 1 & - & 12 \\
\hline Las Pintadas & 1 & - & - & - & - & - & 1 \\
\hline Viluco & 6 & 2 & 8 & - & - & - & 16 \\
\hline Capiz I & 1 & 1 & 1 & - & - & - & 3 \\
\hline La Arboleda II & 1 & - & - & - & - & - & 1 \\
\hline Barrancas & 5 & 2 & 1 & - & - & - & 8 \\
\hline Tacuarí y 20 de Junio & 4 & - & - & - & - & - & 4 \\
\hline Beltrán y Liniers & 1 & - & - & - & - & - & 1 \\
\hline Olascoaga & - & - & - & - & 1 & - & 1 \\
\hline El Algarrobito & 1 & - & - & - & - & - & 1 \\
\hline Estación Lagunas del Rosario & 1 & - & - & - & - & - & 1 \\
\hline Ruinas de San Francisco & 1 & 1 & - & - & - & - & 2 \\
\hline Alberdi e Ituzaingó & - & 2 & - & - & - & 1 & 3 \\
\hline Oeste de Iglesias & 2 & - & - & - & - & - & 2 \\
\hline Valle de Calingasta & 2 & - & - & - & - & - & 2 \\
\hline Barrealito & - & - & 1 & - & - & - & 1 \\
\hline N Total vasijas por morfología & 30 & 11 & 14 & 1 & 2 & 1 & 59 \\
\hline
\end{tabular}

Tabla 3. Vasijas y fragmentos Viluco Inca Mixto analizados por sitio y categoría morfológica. Se discriminan según las influencias en las formas: Chile central y Norte Chico chileno; Inca Cuzqueña.

y en el caso de las vasijas Diaguita patrón Local Fase Inca, algunas medidas fueron aportadas por el autor (Cantarutti com. pers.). En el caso de las escudillas, las medidas indican que los diámetros de borde se superponen, pero la altura máxima es muy inferior en el caso de la cerámica Inca Cusqueña (Tabla 4); en las jarras de los tipos Viluco y Diaguita Patrón Local Fase Inca las medidas del diámetro máximo, el diámetro mínimo y la altura se superponen, mientras que la única medida publicada de los jarros Inca Cusqueño es mayor a los tipos antes mencionados (Tabla 5).

Con base en la evidencia morfométrica planteamos que las jarras y escudillas Viluco presentan influencias de las tradiciones alfareras de Chile central y del Norte Chico chileno, y proponemos que fueron formas incorporadas por los grupos locales a partir del ingreso de mitmaqkuna Diaguita y población Aconcagua de Chile central, quienes eran portadores de tradiciones alfareras que de- sarrollaron antes del ingreso incaico. Se postula que las escudillas y los platos cusqueños, son las formas incaicas que exhiben mayor libertad de expresión estilística en las distintas provincias (Bray 2003), por lo cual, entendemos que las escudillas Viluco no escaparían a este fenómeno, ya que presentan un sincretismo que incluye las formas de origen trasandino preincaico y decoraciones de inspiración local y cusqueña.

Con el objetivo de detectar posibles continuidades entre las tradiciones Viluco y Agrelo - producida localmente en el COA durante el Período Alfarero Medio- comparamos preliminarmente las formas y decoraciones. Los resultados permiten inferir que no hay similitudes entre ambos tipos, ya que las formas características de Agrelo son muy distintas a las Viluco. Agrelo se caracteriza por tener grandes vasijas restringidas (algunas conteniendo restos óseos humanos), de cuerpo globular con base apuntada y truncada, con cuellos rectos y altos, bases plano o pla- 


\begin{tabular}{|c|c|c|c|c|}
\hline \multirow{2}{*}{ Tipo Cerámico } & \multicolumn{4}{|c|}{ Escudillas } \\
\cline { 2 - 5 } & $\begin{array}{c}\text { Diámetro del borde } \\
\text { (mínimo-máximo) }\end{array}$ & $\begin{array}{c}\text { Altura Máxima } \\
\text { (mínimo-máximo) }\end{array}$ & Cantidad de vasijas medidas & Referencia \\
\hline Viluco* $^{*}$ & $139-189 \mathrm{~mm}$ & $51-85 \mathrm{~mm}$ & 9 & Prieto y Chiavazza 2009: 265 \\
\hline $\begin{array}{c}\text { Diaguita patrón Local Fase } \\
\text { Inca*** }\end{array}$ & $105-235 \mathrm{~mm}$ & $35-50 \mathrm{~mm}$ & 6 & Cantarutti com.pers \\
\hline Aconcagua Fase Inca & $195-210 \mathrm{~mm}$ & $55-63 \mathrm{~mm}$ & 7 & Cantarutti y Mera 2002: 166 \\
\hline Inca Cusqueño*** & $100-200 \mathrm{~mm}$ & Aproximadamente $30 \mathrm{~mm}$ & - & Meyers 1975: 15 \\
\hline
\end{tabular}

Tabla 4. Comparación entre las medidas de las escudillas de los tipos cerámicos Viluco Inca Mixto, Inca Cusqueño, Diaguita Patrón Local Fase Inca y Aconcagua Fase Inca. Se presentan las medidas mínimas y máximas de cada tipo de forma. *Se usaron las medidas de la Tabla 2 de Prieto y Chiavazza (2009: 265); **las medidas corresponden a las escudillas identificadas con los números 169, 150, 209, 246, 590, 628 (Cantarutti 2002: 198, Lámina 66, figuras 1 y 2). *** No se especifica la cantidad de vasijas en que se basa este dato.

\begin{tabular}{|c|c|c|c|c|c|}
\hline \multirow{2}{*}{ Tipo cerámico } & \multicolumn{4}{|c|}{ Jarras } \\
\cline { 2 - 6 } & $\begin{array}{c}\text { Diámetro máximo } \\
\text { (mínimo-máximo) }\end{array}$ & $\begin{array}{c}\text { Diámetro máximo } \\
\text { (mínimo-máximo) }\end{array}$ & $\begin{array}{c}\text { Altura máxima } \\
\text { (mínimo-máximo) }\end{array}$ & $\begin{array}{c}\text { Cantidad de vasijas } \\
\text { medidas }\end{array}$ & Referencia \\
\hline Viluco* & $99-148$ & $42-103 \mathrm{~mm}$ & $97-146 \mathrm{~mm}$ & 17 & $\begin{array}{c}\text { Prieto y Chiavazza 2009: } \\
266\end{array}$ \\
\hline $\begin{array}{c}\text { Diaguita Patrón Local Fase } \\
\text { Inca** }\end{array}$ & $142 \mathrm{~mm}$ & $51 \mathrm{~mm}$ & $148 \mathrm{~mm}$ & 1 & Cantarutti com.pers \\
\hline Inca Cusqueño** & - & - & $150-250 \mathrm{~mm}$ & - & Meyers 1975: 12 \\
\hline
\end{tabular}

Tabla 5. Comparación entre las medidas de las jarras de los tipos cerámicos Viluco Inca Mixto,

Inca Cusqueño y Diaguita Patrón Local Fase Inca. Se presentan las medidas mínimas y máximas de cada tipo de forma. ${ }^{*}$ Se usaron las medidas de la Tabla 4. de Prieto y Chiavazza (2009: 267); **las medidas corresponden a la jarra $\mathrm{N}^{\circ} 202$

(Cantarutti 2002, lámina 69, figura 8). ${ }^{* *}$ No se especifica la cantidad de vasijas en que se basa este dato.

no-convexas y con decoraciones geométricas, incisas e imbricadas (unguiculada); vasijas abiertas caracterizadas por tazones, pucos grandes con aletones oblicuos y decoración imbricada, y pucos alisados (Canals Frau 1956; Canals Frau y Semper 1956; Michieli 1974). A la información morfológica y decorativa se suma la de los estudios petrográficos comparativos entre Agrelo y Viluco, los que indican que las pastas de ambos conjuntos fueron preparadas con inclusiones de distinto origen geológico, y además evidencian diferentes tecnologías de cocción (Prieto Olavarría y Castro de Machuca 2015).

Por otra parte, ha sido útil la sistematización reciente de la información de la cerámica Angualasto de la provincia de San Juan. Michieli (2015) propone que la definición del origen y las características de este conjunto aún no se resuelve. Las vasijas Angualasto fueron elaboradas con pastas de coloración rosada a salmón, de textura tosca, con inclusiones de arena gruesa, paredes gruesas, bases plano-convexas o menisco-convexas, superficies alisadas y decoración pintada negra (interior y exterior que representa motivos de diversos atributos del cóndor), escasa presencia de asas horizontales, mamelones y modelados de rostros (alegres y llorosos), y figuras en miniatura (Michieli 2015). Las formas corresponden a: urnas en forma de pera invertida, base apuntada de 34 a $50 \mathrm{~cm}$ de altura y hasta $50 \mathrm{~cm}$ de diámetro máximo; vasijas abiertas, usadas como tapas de urna, de tamaño mediano con bases apuntadas y motivos decorativos que representan al cóndor pintado de negro (interior y exterior), tienen entre 20 y $24 \mathrm{~cm}$ de altura y 36 a $40 \mathrm{~cm}$ de diámetro de boca; vasijas de uso doméstico de tamaño pequeño con bases apuntadas, de 8 a $14 \mathrm{~cm}$ de altura y 11 a $22 \mathrm{~cm}$ de diámetro de boca; vasijas cerradas con cuellos evertidos, asas horizontales, decoradas con motivos de cóndor pintados de negro, de 36 a $48 \mathrm{~cm}$ de altura y $45 \mathrm{~cm}$ de diámetro máximo (Michieli 2015). Un aspecto destacado es que la decoración no se presenta en zonas verticales ni de 
forma geometrizante, ya que cubre toda la superficie y corresponde a una figura completa en sí misma (simétrica o no) y sin patrones repetidos. En palabras de la autora: "Se aprecia el dominio de los motivos que aparentan estar realizados en forma libre, a mano alzada y sin seguir patrones prefijados..." (Michieli 2015: 102). A partir de este análisis preliminar de las descripciones y las láminas (Michieli 2015: 99-102; Láminas 149-156, 164-171, 310326), no observamos atributos similares de forma o de decoración entre la cerámica Angualasto y Viluco, por lo cual no se puede sostener la idea propuesta por García, quien indicó, sin dar detalles, que la cerámica Viluco tenía influencias Angualasto (García 1996).

\section{Tendencias de distribución de las formas Viluco}

La contrastación de la evidencia Viluco con las diferentes formas del equipo culinario en las provincias incaicas (Bray 2003, 2004), permite realizar una aproximación exploratoria a las tendencias de representación de las diferentes formas en el COA con las del resto del Imperio.

En las provincias, el aríbalo fue una forma relevante y representa casi la mitad del número total de las vasijas (Bray 2004). Por ejemplo, en el sector chileno del Kollasuyu (sitios El Plomo y La Reina) están ampliamente representados (Bray 2003). Por el contrario, en Mendoza y San Juan solo se encontraron dos ejemplares de aríbalos Viluco (Debenedetti 1917). En otras zonas de la periferia imperial, esta forma fue importante, ya que se asoció al almacenamiento, transporte y servicio de chicha, bebida socialmente indispensable en los Andes (Bray 2003).

Los platos y las ollas con pie son las otras formas cusqueñas ampliamente representadas en las provincias, porque fueron parte fundamental del conjunto cerámico de cualquier individuo o grupo afiliado al Estado inca viviendo en las regiones interiores (Bray 2004). En Mendoza, la presencia de platos con decoración modelada ornitomorfa se registra en los tambos incaicos del valle de Uspallata (Bárcena 2002, Bárcena y Román 1990), pero no se pueden considerar de tradición Viluco, ya que se manufacturaron otros tipos cerámicos y con una organización centralizada de la producción (Bárcena y Román 1990). Por su parte, las ollas con pie, identificadas como vasijas para cocinar ligadas a la identidad incaica en las actividades diarias más bá- sicas (Bray 2003), son muy escasas en los contextos Viluco, ya que solo se ha recuperado un fragmento en un contexto doméstico colonial (siglo XVII) del valle de Mendoza (sitio Alberdi e Ituzaingó) (Prieto Olavarría 2010a; Prieto Olavarría y Chiavazza 2010).

En el conjunto Viluco, las formas más representadas son las jarras, los vasos y las escudillas (Tabla 3), una situación muy distinta a la descrita para otras provincias. En los contextos domésticos Viluco, las escudillas, con decoración modelada o sin ella, son las formas más abundantes (Prieto Olavarría 2012). Las jarras son las más representadas en los contextos funerarios y segundas en abundancia entre los domésticos. Desde esta perspectiva y considerando que son vasijas con atributos semejantes a las tradiciones alfareras trasandinas Diaguita y Aconcagua, planteamos que su abundancia se relaciona con la importancia que tuvieron entre las poblaciones locales las tradiciones alfareras de los grupos que se trasladaron desde los valles chilenos hasta el COA.

Los vasos o kero, fueron vasijas para beber chicha (Mulvany 2004) y su función fue más bien especializada o limitada, ya que están escasamente representados en la capital imperial y en las provincias, especialmente en el Kollasuyu (Bray 2003). En este caso de estudio se observa una notable diferencia, ya que en los contextos funerarios Viluco los kero son la segunda categoría morfológica más representada (Tabla 3). A esto se suma la presencia de dos kero con asa, variación que podría ser de origen local. La abundancia de esta forma se contrapone con la escasez de aríbalos, ya que ambos son indicadores del consumo de chicha. En este sentido, la evidencia recuperada en sitios domésticos no permite agregar más datos, ya que los kero y los aríbalos no son fácilmente identificables en los conjuntos fragmentarios (Prieto Olavarría 2012).

Análisis de las asas y las decoraciones modeladas

Las decoraciones modeladas están presentes en las escudillas y jarras Viluco (Tabla 6) y ampliamente representadas en la cerámica cusqueña (Bingham 1930; Fernández Baca 1971).

Todas las escudillas Viluco recuperadas en los contextos 


\begin{tabular}{|c|c|}
\hline Vasijas & Decoraciones modeladas \\
\hline Escudilla 1219 & Apéndice ornitomorfo con un par de protuberancias localizadas en el extremo opuesto del borde \\
\hline Escudilla 10335 & Apéndice ornitomorfo con un par de protuberancias localizadas en el extremo opuesto del borde \\
\hline Escudilla 10336 & Apéndice ornitomorfo con un par de protuberancias localizadas en el extremo opuesto del borde \\
\hline Escudilla 199 & Tres protuberancias opuestas sobre el borde \\
\hline Escudilla 211 & Asa vertical en arco sobre el borde \\
\hline Escudilla E16-1 & Cuatro protuberancias opuestas sobre el borde \\
\hline Escudilla 8077 & Apéndice fracturado sobre el borde \\
\hline Escudilla 3993 & Asa horizontal sobre el borde \\
\hline Fragmentos de escudilla 13273-13277 & Asa horizontal con incisiones sobre el borde \\
\hline Fragmento de escudilla 778 & Apéndice de cabeza de camélido sobre el borde \\
\hline Fragmento de escudilla 1160 & Apéndice de cabeza de camélido sobre el borde \\
\hline Jarra MAF119-120 & Una protuberancia en el sector inferior del asa \\
\hline Jarra 1604 & Una protuberancia en el sector superior del asa \\
\hline Jarra 3912 & Dos protuberancias en el asa, una en el sector superior y la otra en el sector inferior \\
\hline Jarra 1216 & Una protuberancia en el sector inferior del asa \\
\hline
\end{tabular}

Tabla 6. Decoraciones modeladas en las escudillas y jarras Viluco Inca Mixto

funerarios presentan decoraciones modeladas. Las más comunes son las cabezas estilizadas zoomorfas al igual que en las escudillas incaicas (Bray 2003; Meyers 1975). Las asas ornitomorfas con dos protuberancias o apéndices ubicadas en el sector opuesto del borde son las más representadas en el conjunto local. Otra decoración de inspiración cusqueña, son los conjuntos de dobles protuberancias opuestas en el borde, las asas verticales en arco y las asas horizontales incisas (Figuras $2 \mathrm{G}$ y $3 \mathrm{~A}$ ). Estas dos últimas se incluirían dentro de las "vertical and horizontal loop handles" descritas por Bray (2003), las que no son frecuentes en el Imperio. Por otra parte, las asas horizontales con incisiones presentes en las escudillas Viluco no tienen correlato en tipos cerámicos del NOA ni en Chile, aunque están presentes en recipientes de piedra hallados entre los ríos Huasco y Choapa que habrían sido parte de los regalos entregados a los jefes locales como reconocimiento a la alianza que establecieron con los incas para expandir el Tawantinsuyu hacia territorios más meridionales. ${ }^{9}$

En los contextos domésticos Viluco son mayorita-

9 Imágenes y explicación de los regalos de piedra en la página del Museo Chileno de Arte Precolombino http://www.precolombino.cl/exposiciones/exposiciones-temporales/chile-bajo-el-imperio-inka-2009/el-inka-en-las regiones/regalos-de-piedra/ rias las escudillas sin apéndices, si bien se encontraron fragmentos de borde con protuberancias, con asas verticales en arco y con asas horizontales incisas (Prieto Olavarría 2012). Evidencia extraordinaria es el caso de dos fragmentos de escudillas con apéndices de cabezas camélidos, únicas en su tipo en el COA (Figura $3 \mathrm{~B}$ ), y que fueron recuperadas en un contexto doméstico de la ciudad de Mendoza colonial, junto al fragmento de la olla con pie antes mencionado. La representación de cabezas de camélidos es usual en los platos y escudillas cusqueñas (Bingham 1930; Fernández Baca 1971), por lo cual inferimos que su presencia en Viluco es de influencia cusqueña, lo que refuerza la idea del rol simbólico de la cerámica Viluco en la temprana ciudad colonial, más allá de la evidencia de los contextos funerarios del norte y centro de la provincia (Prieto Olavarría 2012).

Las decoraciones modeladas también se encuentran en cuatro jarras Viluco que tienen una o dos protuberancias en el sector inferior y/o superior del asa. La jarra 1216 posee, además del protúbero en el sector inferior, incisiones a lo largo del asa (Figura 4A y B). Estas decoraciones son similares a los modelados presentes en diversos tipos alfareros hallados en Chile, y aunque no es posible determinar qué tradiciones influyeron en Viluco, sí planteamos que los modelados en las asas de las jarras fueron la manifestación local de una tradición decorativa que tras- 


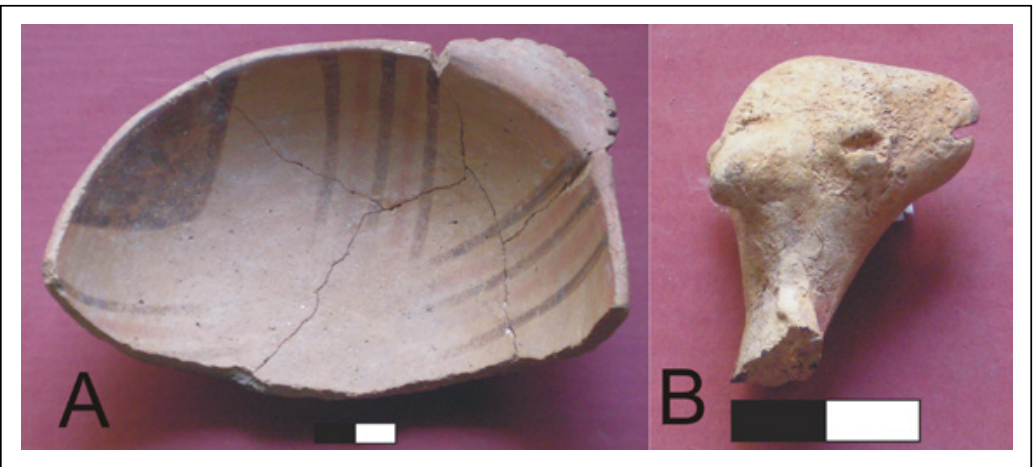

Figura 3. Escudillas Viluco Inca Mixto con decoraciones modeladas. A) fragmentos de escudilla 13273-13277 con asa horizontal y patrón cuatripartito basado en clepsidra (sitio doméstico de Ruinas de San Francisco); B) fragmento de escudilla 778 con apéndice zoomorfo (cabeza de camélido) (sitio doméstico Alberdi e Ituzaingó).

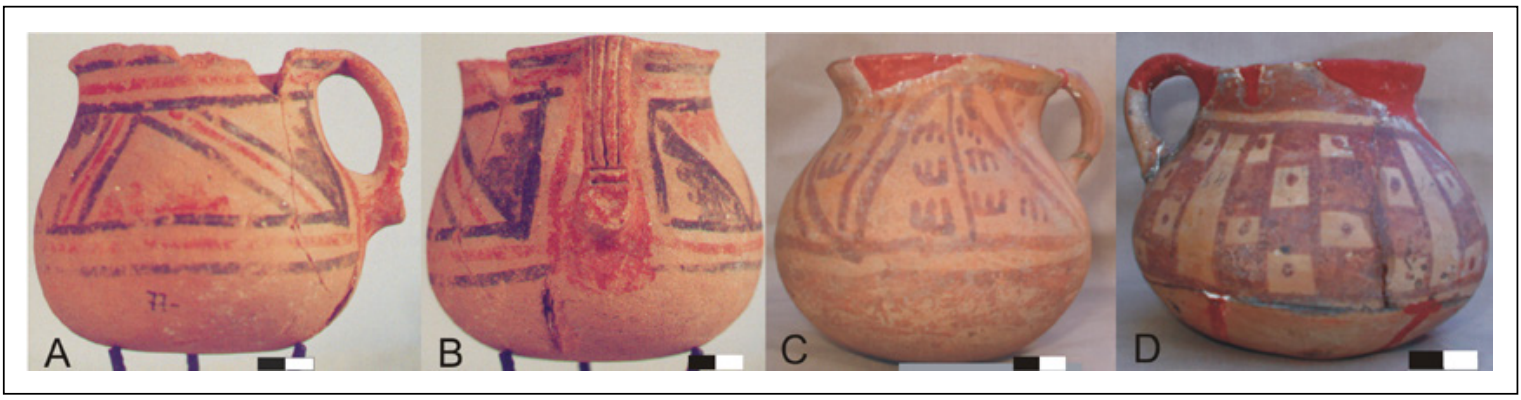

Figura 4. Jarras Viluco Inca Mixto decoradas. A y B) jarra 1216 con decoración modelada e incisiones en el asa, incluye el patrón zigzag B2 y líneas rectas con patrón de traslación vertical (sitio de Beltrán y Liniers); C) jarra 3911 con motivo en forma de E, incluye el patrón zigzag D (contexto funerario de Tacuarí y 20 de Junio); D) jarra 204 con patrón ajedrezado (cementerio de Viluco).

ciende al período incaico en diversos sectores del Área Andina. Por ejemplo, si se consideran las influencias de las culturas de Arica en la cerámica Viluco que propuso Lagiglia (1978), existen protuberancias en las jarras de los tipos Cabuza, Maytas Chiribaya y San Miguel (Uribe 1998). En cuanto a la evidencia en áreas más cercanas, se observan protuberancias modeladas en las asas en cerámica procedente de Chile encontrada en la alta cordillera del sudoeste de San Juan (Michieli 1998).

\section{Análisis de la decoración pintada}

Un aspecto relevante de la decoración pintada Viluco es su carácter no figurativo y geométrico. De acuerdo a las investigaciones enfocadas en los sistemas visuales de registro y comunicación andinos, la estética inca se caracteriza por la abstracción, enfatizando el diseño geométrico y la repetición (Cummins 2002: 25, 2007; Frame 2007; Quispe-Agnoli 2005; Timberlake 2008). La abstracción se refiere a un conjunto de formas geométricas altamente regularizadas que guardan una relación convencional con objetos o seres, por lo cual las vasijas inca estaban ligadas de modo abstracto a la cultura imperial (Cummins 2002).

El análisis de simetría de la decoración pintada Viluco se realizó en 51 vasijas y permite identificar $18^{10}$ patrones simétricos de decoración con sus respectivas variantes

10 El patrón faja19, no posee motivo ni simetría, ya que no hay unidad mínima (motivo) superpuesta sobre sí misma, por lo cual no existe un patrón simétrico. La denominamos patrón, debido a su recurrencia en las vasijas, especialmente a lo largo del sector del borde. 


\begin{tabular}{|c|c|c|c|c|c|}
\hline \multirow{2}{*}{ Cantidad de patrones } & \multicolumn{5}{|c|}{ Formas y cantidad } \\
\cline { 2 - 6 } & $\begin{array}{c}\text { Jarra } \\
\mathbf{N = 2 9}\end{array}$ & $\begin{array}{c}\text { Escudilla } \\
\mathbf{N = 7}\end{array}$ & $\begin{array}{c}\text { Vaso o kero } \\
\mathbf{N = 1 2}\end{array}$ & $\begin{array}{c}\text { Botella cuello corto } \\
\mathbf{N = 1}\end{array}$ & $\begin{array}{c}\text { Cántaro o aríbalo } \\
\mathbf{N = \mathbf { 2 }}\end{array}$ \\
\hline Uno & 11 & 5 & 4 & 1 & 2 \\
\hline Dos & 13 & 2 & 5 & - & - \\
\hline Tres & 1 & - & 1 & - & - \\
\hline Cuatro & 4 & - & - & - & - \\
\hline Cinco & - & - & 2 & - & - \\
\hline
\end{tabular}

Tabla 7. Cantidad de patrones decorativos por categoría morfológica en las vasijas Viluco Inca Mixto

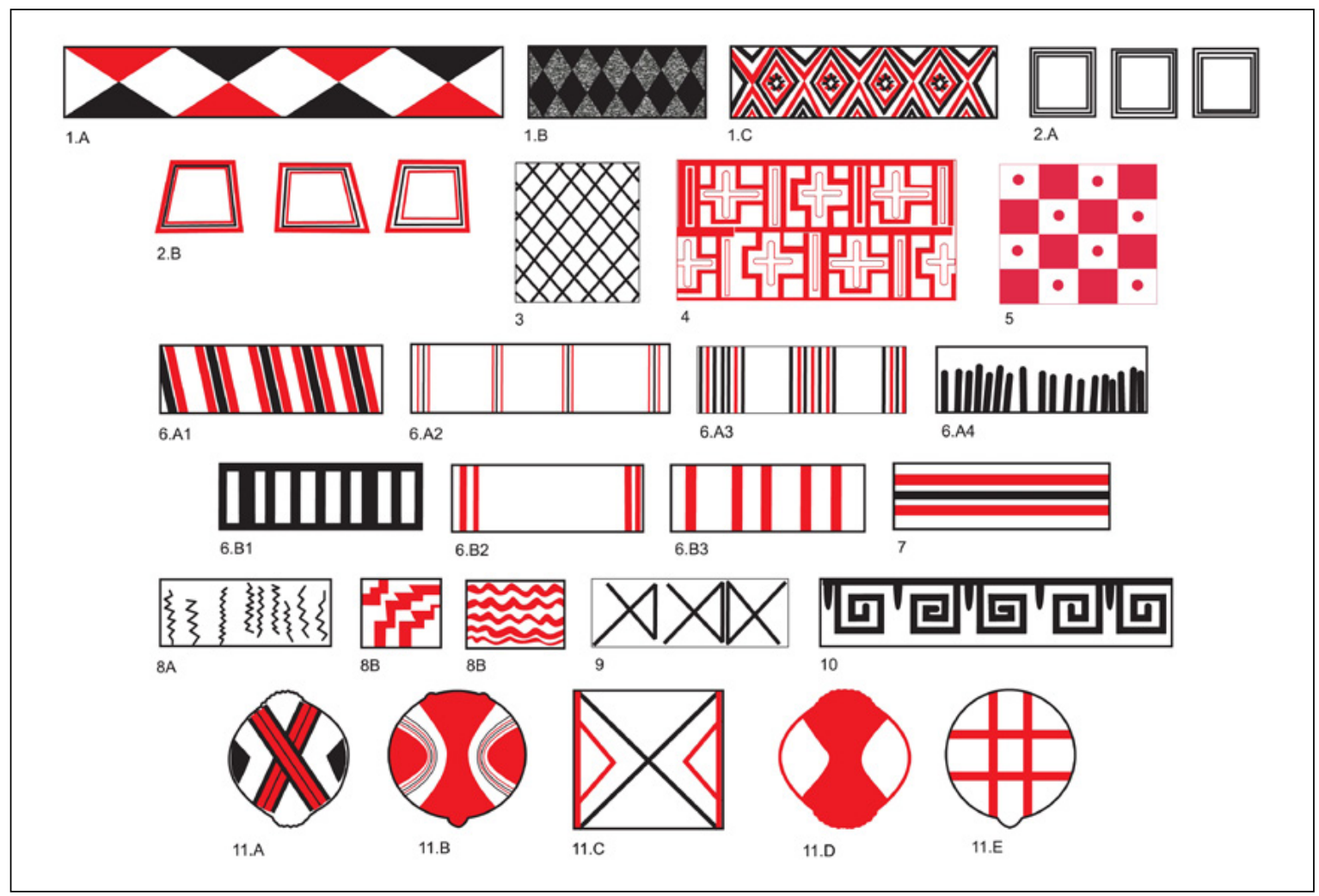

Figura 5. Patrones decorativos cusqueños hallados en la cerámica Viluco Inca Mixto. Los números corresponden a los patrones descritos en la Tabla 8.

y subvariantes, los que están representados en distintas frecuencias y se presentan combinados, uno o varios en una misma vasija, en jarras, keros y escudillas (Tabla 7) (Figura 5). ${ }^{11}$ En todos los casos, los patrones están dispuestos sobre las superficies de manera horizontal, generando así la banda de diseño.

Siguiendo la clasificación de Fernández Baca (1971), 10

11 Para conocer en detalle las unidades y motivos decorativos definidos para la cerámica Viluco, consultar la tesina de licenciatura de Tobar (2013). de estos patrones están representados en la iconografía cusqueña (Tabla 8) (Figura 5) y varios motivos Viluco (cruz, clepsidra, cuadrado, rombos, estrella, doble escalonado y la línea que forma variantes del patrón zigzag -Zigzag A1, Zigzag A2-) también están en los tokhapu de la cerámica incaica (Cummins 2002; Frame 2007; entre otros) y en pinturas coloniales del Cusco de los siglos XVI y XVII (Timberlake 2008).

La mayor parte de los patrones cusqueños presentes en 


\begin{tabular}{|c|c|c|c|c|}
\hline $\begin{array}{l}\text { Patrones de diseño de la } \\
\text { cerámica Viluco }\end{array}$ & $\begin{array}{l}\text { Cantidad de vasijas con el } \\
\text { patrón de diseño }(\mathrm{N})\end{array}$ & $\begin{array}{l}\text { Porcentaje de vasijas } \\
\text { con el patrón de } \\
\text { diseño }(\%)\end{array}$ & $\begin{array}{l}\text { Origen propuesto del } \\
\text { patrón de diseño }\end{array}$ & $\begin{array}{c}\text { Otros tipos cerámicos en } \\
\text { que se encuentra el patrón } \\
\text { de diseño }\end{array}$ \\
\hline 1) Rombos en traslación $\left(^{*}\right)$ & 3 & 5,88 & Inca Cusqueño & Diaguita Inca \\
\hline $\begin{array}{l}\text { 2)Patrón polígonos concéntricos } \\
\text { en traslación }\left(^{* *}\right)\end{array}$ & 2 & 3,92 & Inca Cusqueño & - \\
\hline 3)Reticulado oblicuo & 1 & 1,96 & Inca Cusqueño & Diaguita Inca \\
\hline 4) Cruces en traslación & 1 & 1,96 & Inca Cusqueño & Diaguita Inca \\
\hline 5) Ajedrezado & 1 & 1,96 & Inca Cusqueño & Diaguita Inca \\
\hline $\begin{array}{c}\text { 6) Líneas rectas en traslación } \\
\text { horizontal }\end{array}$ & 13 & 25,49 & Inca Cusqueño & Diaguita Inca \\
\hline $\begin{array}{l}\text { 7) Líneas rectas en traslación } \\
\text { vertical }\end{array}$ & 12 & 23,53 & Inca Cusqueño & Diaguita Inca \\
\hline 8) Líneas onduladas en traslación & 3 & 5,88 & Inca Cusqueño & Diaguita Inca \\
\hline 9) Clepsidra en traslación vertical & 1 & 1,96 & Inca Cusqueño & Diaguita Inca \\
\hline 10) Grecas en traslación & 1 & 1,96 & $\begin{array}{c}\text { Inca Cusqueño/ } \\
\text { Diaguita II (preincaico) }\end{array}$ & - \\
\hline 11) Cuatripartición $(* * *)$ & 5 & 9,80 & Inca Cusqueño & Diaguita Inca \\
\hline 12) Zigzag $(* * * *)$ & 17 & 33,33 & - & - \\
\hline 13) Doble Zigzag & 1 & 1,96 & - & - \\
\hline $\begin{array}{c}\text { 14) Patrón Doble escalonado en } \\
\text { Zigzag }\end{array}$ & & & - & - \\
\hline 15) Escalonado en hileras & 1 & 1,96 & - & - \\
\hline 16) Escalonado en traslación & 3 & 5,88 & - & - \\
\hline $\begin{array}{l}\text { 17) Escalonado en rotación y } \\
\text { traslación }\end{array}$ & 1 & 1,96 & - & - \\
\hline 18) Cuadrado en traslación $(* * * * *)$ & 8 & 15,69 & - & - \\
\hline 19) Faja & 19 & 37,25 & - & - \\
\hline
\end{tabular}

Tabla 8. Patrones de diseño de la cerámica Viluco Inca Mixto. El análisis se hizo sobre 51 vasijas

(*) Patrón rombos en traslación, incluye las variantes rombos en cadena, rombos en hilera y rombos concéntricos en hilera; $\left.{ }^{* *}\right)$ incluye dos variantes: patrón cuadrados concéntricos en traslación y patrón trapecios concéntricos en traslación; (***) cuatripartición, incluye las variantes cuatripartición en base a clepsidra, clepsidra inserta en cuadrado y cuatripartición en cruz; ( ${ }^{* * *}$ ) patrón zigzag, incluye las variantes $\mathrm{A}, \mathrm{B}, \mathrm{C}, \mathrm{D}, \mathrm{E}, \mathrm{F}, \mathrm{G}$; $\left(^{* * * * *}\right)$ patrón cuadrados en traslación, incluye las variantes $\mathrm{A}, \mathrm{B}, \mathrm{C}, \mathrm{D}, \mathrm{E}, \mathrm{F}$.

Viluco están representados en la cerámica Diaguita Inca (Tabla 8) (siguiendo a González Carvajal 2004a, 2004b). Esta evidencia nos permite proponer que estos diseños ingresaron al COA a través de los mitmaqkuna diaguita. Existen algunas excepciones, como dos variantes Viluco del patrón polígonos concéntricos en traslación (variante cuadrados concéntricos y variante trapecios concéntricos en traslación), las que no se registran en la cerámica Diaguita y serían influencia de otros grupos ligados al Imperio o variaciones desarrolladas localmente.

En la alfarería Diaguita Inca, generalmente las estructu- ras de los patrones son simples, ya que la mayoría solo presenta un principio simétrico que es la traslación y en menor representación la rotación combinada con la traslación y la doble reflexión especular (González Carvajal 2008). En los patrones cusqueños de la cerámica Viluco también se presenta esta configuración: traslación, doble reflexión especular (dos ejes de simetría, uno horizontal y otro vertical, o dos ejes diagonales) y simetría rotatoria. Además, tanto en el conjunto Diaguita (González Carvajal 1998) como en el Viluco, el patrón cuatripartición en cruz solo está en las vasijas no restringidas (pucos, 


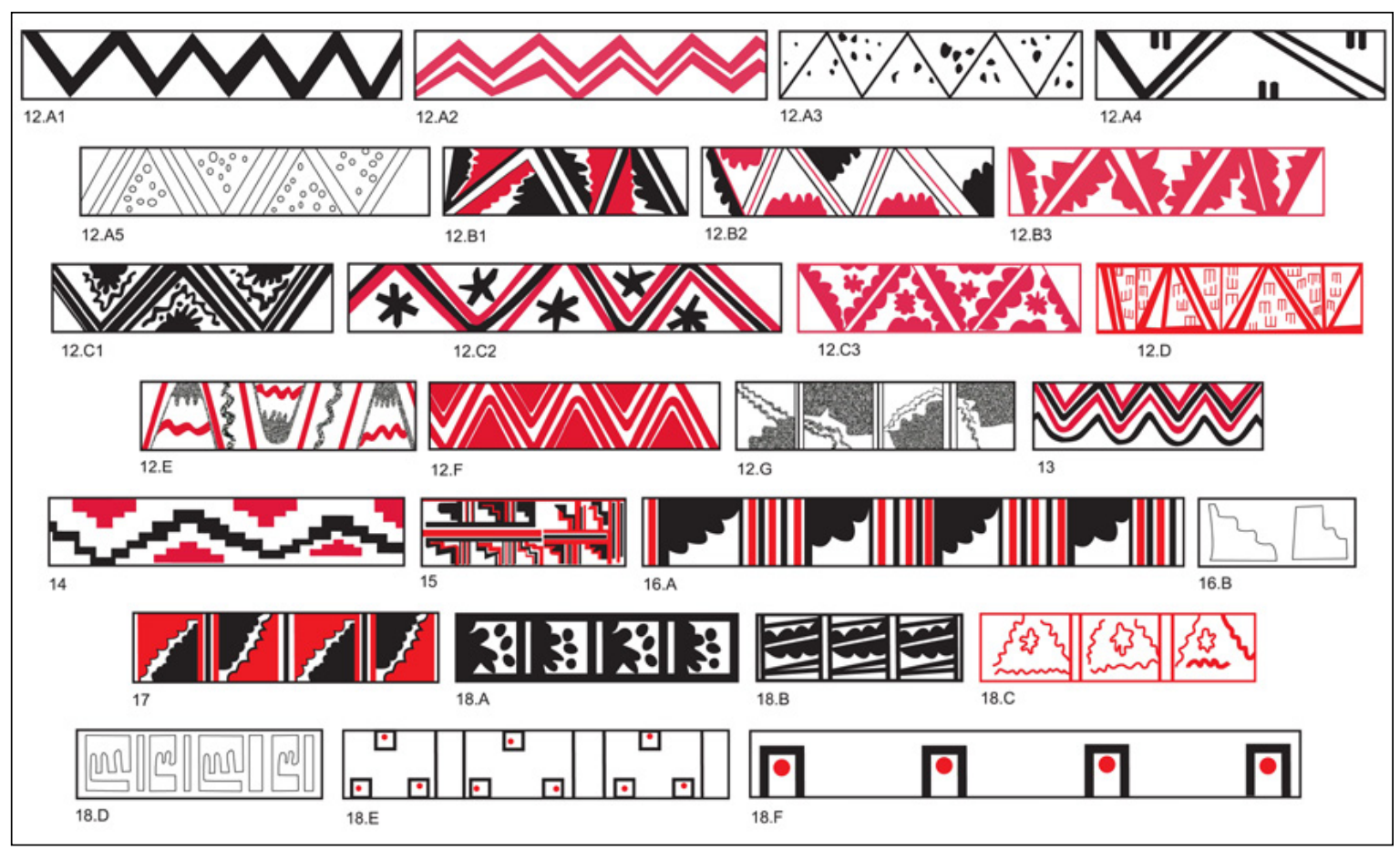

Figura 6. Patrones de diseño no cusqueños hallados en la cerámica Viluco Inca Mixto. Los números corresponden a los patrones descritos en la Tabla 8.

platos playos y platos ornitomorfos) (Figura 5). Como información complementaria, mencionamos que este patrón cuatripartito, en el que se cruzan diametralmente dos pares de líneas paralelas, también está representado en dos escudillas halladas en Chile central como parte de ajuares funerarios de la población local durante el período de dominación incaica (Cantarutti y Mera 2002). Por otra parte, el motivo Viluco de grecas en traslación, se halla tanto en la cerámica cusqueña como en el sistema representacional Diaguita anterior al período incaico (González Carvajal 2008). Desde esta perspectiva, este diseño pudo ingresar con los mitmaqkuna Diaguita u otras poblaciones.

De los 18 patrones decorativos Viluco (con sus variantes y subvariantes), ocho se relacionan con los imperiales (Tabla 8) (Figura 6) y algunos motivos aislados están en la cerámica y los textiles inca: escalonados, línea que forma el zigzag, cuadrado con punto incluido, estrella. Del total de vasijas Viluco analizadas, la mitad posee patrones cusqueños y no cusqueños, mientras que la otra mitad presenta solo no cusqueños. El más representativo de los patrones no cusqueños, ya que está en 17 vasijas Viluco, es el patrón zigzag con sus variantes internas y no se puede precisar su origen, ya que se encuentra representado en diversas tradiciones y en cada una de ellas adopta estructuras singulares: el zigzag está presente en diversos soportes imperiales y también en la cerámica Diaguita Clásico que se proyecta hasta el Diaguita Inca (González Carvajal 2004a). Dos ejemplos de esta complejidad son: los patrones Viluco zigzagAl y zigzagA2, que son similares, pero no idénticos, a los patrones zigzag cusqueños y Diaguita Inca; las estructuras complejas basadas en la combinación de más de un principio simétrico a la vez, como el principio simétrico de reflexión desplazada más traslación que caracteriza al patrón zigzag Viluco y que es característico de los patrones de diseño del arte visual diaguita previo al ingreso inca (González Carvajal 2008).

Entre los motivos decorativos, hay un caso que permite seguir reflexionando sobre el origen de las influencias, de las interpretaciones locales de cada elemento y de las estructuras decorativas. Se trata del motivo en forma de E incluido en el patrón zizgzagD de la vasija 3911 (ver Figura 4), característico del estilo Inca Paya del Valle Calchaquí (NOA), uno de los más distribuidos por el 
Estado inca (pucos, platos, aríbalos y jarras) en el NOA, Chile y Bolivia (Williams 2008). Consideramos que esta evidencia amplía al NOA el espectro de tradiciones que influyeron en la cerámica Viluco y conduce a cuestionarnos respecto al modo en que estos atributos decorativos puntuales pudieron ingresar al COA.

Otro aspecto relevante en los patrones Viluco es la alternancia de colores (Prieto y Chiavazza 2009). En este estudio observamos que el patrón líneas rectas en traslación vertical presenta una línea que se traslada tres veces alternando el color y combinando rojo/negro/rojo. Esta configuración también se presenta en el patrón líneas en traslación horizontal, pero en este caso es el conjunto de tres de ellas el que se traslada como un todo. Además, cuando el número de líneas que se traslada horizontalmente como un todo es siete, el centro siempre es rojo y los bordes son negros. Otros diseños donde se registra la combinación rojo y negro, es el patrón escalonado en rotación y traslación -donde siempre cambia de color el escalonado- y en algunas variantes del patrón zigzag: a través de un eje de reflexión vertical; de una reflexión desplazada (zigzag $\mathrm{B} 1$ ); de una reflexión desplazada en el otro (zigzag B2).

La decoración pintada de las piezas gemelas recuperadas en el cementerio indígena colonial de Agua Amarga (valle de Uco, centro de Mendoza) fue destacada en trabajos anteriores (Prieto y Chiavazza 2009). La correspondencia en los patrones de diseño de los pares de vasijas llevó a postular que las dos jarras y los dos keros eran piezas idénticas a nivel morfométrico y decorativo, mientras que las escudillas presentaban variaciones en la decoración pintada y solo eran iguales en la forma (Prieto y Chiavazza 2009). Los resultados del análisis de simetría que presentamos en este trabajo, permiten definir la correspondencia decorativa en todos los casos: las jarras presentan el patrón local zigzag B3 en el sector del cuello y en la parte superior y media del cuerpo (la unidad mínima es un triángulo con un par de escalonados opuestos incluidos que se traslada por reflexión desplazada); los kero tienen dos patrones cusqueños, el patrón líneas rectas en traslación horizontal (en número de siete) y líneas rectas en traslación vertical (en número de tres), y el patrón escalonado en traslación cuya unidad mínima (escalonado) está presente tanto en los patrones Diaguita Inca como en la cerámica Inca Cusqueña; en las escudillas, el análisis revela que ambas piezas sí se corresponden a nivel de las estructuras del diseño a pesar de que los motivos no son idénticos, ya que ambas poseen doble reflexión especular y simetría rotatoria que expresan la cuatripartición: escudilla 10335, patrón cuatripartición en base a clepsidra; escudilla 1219, patrón cuatripartición en cruz.

Entendemos que la presencia de vasijas gemelas es significativa en el contexto indígena colonial de frontera como el de Agua Amarga, ya que este conjunto habría estado ligado al anterior poder incaico en esa área, la cual fue definida como el límite con los grupos indígenas no sometidos que habitaban el sur (Bárcena 2002). Durante el Imperio inca, las vasijas pares estuvieron connotadas de significado entre los grupos que formaron parte de él, especialmente los keros y las escudillas (Bingham 1930, Rowe 1961); por ejemplo, los kero gemelos fueron regalos del Inka a la nobleza y a quienes sirvieron al Estado (Cummins 2007). Desde esta misma perspectiva se puede analizar la decoración de la jarra 204, recuperada del cementerio de Viluco, ubicado también en la zona de frontera hispano-indígena. Esta pieza posee el patrón ajedrezado, el cual se vincula al poder militar, a la conquista incaica y propio de los altos rangos del ejército (Quispe-Agnoli 2005; Williams 2008).

Discusión sobre la decoración pintada Viluco como lenguaje visual

El estudio de los diseños de la decoración pintada de las vasijas Viluco nos conduce a explorar los contenidos semánticos de los patrones detectados, para lo cual son fundamentales los estudios sobre los lenguajes visuales andinos, específicamente los incaicos, enfocados desde la etnohistoria, la etnografía y la arqueología, que plantean una continuidad entre los códigos gráficos del período incaico y los coloniales (Cummins 2002; Frame 2007; Martínez Cereceda 2008).

A partir del análisis de las estructuras simétricas de la decoración pintada Viluco, proponemos que el espacio del diseño es uno organizado a través de los principios de simetría y donde hay otros elementos significantes como las propiedades del color, el número y la concentricidad. Algunos de los patrones encontrados en Viluco (rombos en cadena, rombos en hilera, rombos concéntri- 
cos en hilera, las clepsidras de los diseños finitos, clepsidra inserta en cuadrado y las figuras cuadrangulares concéntricas en traslación) fueron identificados en otros soportes que circularon en el Imperio, incluida la cerámica Inca Cusqueña, e interpretados como comunicadores de ideas relativas a la dualidad y la cuatripartición (Fernández Baca 1971, Frame 2007). En el caso del patrón cuatriparticional basado en clepsidra detectado en las escudillas Viluco, se observan dos principios simétricos, la reflexión especular y la rotación. El primero indicaría de manera diagramática divisiones espaciales, mientras que el segundo encarna la alternancia secuencial a través del tiempo, por lo que cuando los dos movimientos están presentes se conjugan las nociones de espacio y tiempo (Frame 2007). Del mismo modo, algunos motivos de influencia cusqueña presentes en los patrones Viluco (rombo, clepsidra inserta en cuadrado), fueron interpretados como la representación diagramática de divisiones espaciales, como el motivo del rombo que tiene dos ejes de reflexión invisibles (uno vertical y otro horizontal) y lo divide en cuatro sectores, junto con una simetría rotatoria, lo que fue definido como la representación gráfica del orden sociopolítico del Tawantinsuyu (Frame 2007).

Otras estrategias de comunicación visual relacionadas con la organización incaica, como el rombo y la clepsidra (Frame 2007), están presentes en la cerámica Viluco (en este caso la clepsidra posee doble rotación). Los motivos concéntricos de la cerámica Viluco (rombo, cuadrados y trapecios concéntricos), son interpretados en los registros incas como expresiones de la secuencia jerárquica de estructuras encajadas unas en otras (los suyu dentro de dos mitades y éstas dentro del Imperio) y la oposición en pares de centro/periferia (Frame 2007). También se menciona que simbolizarían ideas de igualdad (misma forma) y jerarquía (dimensiones diferentes) (Cummins 2002).

Respecto a la alternancia de los colores rojo y negro de Viluco, éste es un atributo que ha sido identificado en los tokhapu, donde el color se organiza de forma significativa en oposiciones complementarias (claro/oscuro, apagado/ vivo) o en secuencias (claro a oscuro o viceversa) (Frame 2007). En cuanto a la propiedad numérica, se observó que en el patrón líneas rectas en traslación (horizontal o vertical), las líneas se estructuran numéricamente y se trasladan como un todo par ( 2 y 4$)$ o impar $(3,5$ o 7 ). Al respecto, existen menciones sobre el uso de numerales como el 2, 3, 4, 5, 8, en los códigos andinos tokhapu y tendrían significados culturales asociados a ideas como dualidad, referencias míticas u ordenamientos espaciales (Frame 2007; Timberlake 2008).

A modo de discusión, consideramos que, aunque no es posible hacer una extrapolación directa a los patrones de Viluco de aquellos significados descritos para otros conjuntos y soportes, los resultados nos permiten inferir que Viluco tiene motivos y patrones de simetría, numéricos y de color, característicos del sistema simbólico incaico y que fueron los agentes de significación. Incluso, hay representaciones que están ligadas a los conceptos de dualidad y cuatripartición, los que tienen significados concretos como parte del sistema de comunicación visual andino. Con base en esta evidencia, postulamos preliminarmente que los diseños de la decoración pintada Viluco serían una manifestación local de los códigos gráficos andinos.

\section{$*$ Conclusiones}

El análisis de los atributos de forma y decoración de la cerámica Viluco Inca Mixto nos permite delinear con mayor precisión cuáles fueron las tradiciones cerámicas que ingresaron al COA y se instalaron en las prácticas alfareras de las poblaciones locales, como parte de los procesos de interacción con los grupos trasladados durante la dominación inca. Desde esta perspectiva, el estudio se orientó a definir las similitudes entre este conjunto alfarero y los tipos cuyos productores y consumidores habrían estado involucrados en la dominación imperial en esta área meridional. Los resultados permiten proponer que en la cerámica Viluco confluyeron formas, decoraciones modeladas, motivos y estructuras del diseño decorativo de los tipos cerámicos Inca Cusqueño, Diaguita (preincaico y Diaguita Inca), Aconcagua (preincaico y de Fase Inca) y de otras tradiciones cerámicas del Área Andina, las que fueron reelaboradas por los artesanos locales. Con base en esta evidencia, planteamos que el tipo Viluco es una expresión meridional de la tradición alfarera andina, y por lo tanto se incluye en un sistema de códigos gráficos andinos en tiempos de dominación inca, la cual se proyectó hasta el primer siglo de la Colonia española. Además, la detección de atributos de formas y patrones decorativos cuyo origen estaría en las tradiciones alfare- 
ras trasandinas, permite reafirmar la idea de la dominación incaica en el COA ejercida por grupos trasladados desde el Norte Chico y los valles centrales chilenos. Esta evidencia se corresponde con lo planteado para los valles de Mendoza y San Juan, los que durante el Tawantinsuyu habrían sido espacios dinámicos de interacción étnica y cultural, debido a la concentración de población huarpe y mitmaqkuna, y entre los que posiblemente hubo artesanos especialistas (Bárcena y Román 1990).

La presencia de atributos decorativos inspirados en tipos cerámicos que tuvieron una amplia distribución en el Imperio, como el motivo en forma de E característico de la cerámica Inca Paya, nos lleva a considerar que en el COA también circularon conocimientos de tradiciones cerámicas características del NOA. La diversidad de atributos de forma y decoración presentes en Viluco tiene su correlato en las pastas usadas para su manufactura, ya que uno de sus grupos de pasta se caracteriza por poseer altos porcentajes de inclusiones piroclásticas (tefra volcánica) (Prieto Olavarría y Castro de Machuca 2017), práctica que tuvo una amplia distribución durante el período de dominación inca tanto en el NOA como en el COA, y que habría estado relacionada con estrategias de dominación en las áreas meridionales y fronterizas del Imperio (Prieto Olavarría y Páez 2015).

Respecto a las decoraciones que no pudimos adscribir a tipos cerámicos específicos, como el patrón zigzag y las asas modeladas de las jarras, consideramos que los artesanos locales reelaboraron atributos decorativos de aquellas tradiciones que tuvieron amplia dispersión en el Área Andina. En cuanto a la propuesta de atributos Agrelo y Angualasto presentes en la cerámica Viluco (García 1996), planteamos que, en el estado actual de las investigaciones, no es posible sostener la existencia de similitudes con esos conjuntos alfareros: no se observa continuidad con las formas y decoraciones Agrelo, lo cual se refuerza en las diferencias petrográficas detectadas en el origen geológico de las inclusiones de ambos tipos (Prieto Olavarría y Castro de Machuca 2015a); no hay elementos en las formas y las decoraciones Viluco que permitan inferir influencias de la cerámica Angualasto de San Juan. En este sentido, entendemos que comparaciones más detalladas, solo podrán realizarse cuando se profundicen los estudios de forma, función, decoración y tecnología de todos los tipos cerámicos del COA y de las áreas vecinas.

Los resultados obtenidos refuerzan la idea de que la cerámica Viluco es un conjunto politético, que evidencia múltiples influencias relacionadas con el carácter periférico del COA y cuya abundante presencia, contrapuesta con la escasa representación de vasijas Inca Cusqueño u otros tipos connotados de la legalidad incaica, se relaciona con la tardía anexión de este territorio al Tawantinsuyu y su carácter meridional y fronterizo. Considerando que en las zonas alejadas del centro imperial hubo poco control de los productos elaborados (D'Altroy et al. 1994) y, que las poblaciones en posición subalterna en contextos de colonización encontraron medios indirectos de representación en los nuevos campos de relaciones de poder (Quispe-Agnoli 2005), es posible analizar la cerámica Viluco como un conjunto que tuvo un rol importante en la materialización de la legitimidad imperial entre las poblaciones locales, especialmente en el proceso de reestructuración de las jerarquías locales. Si estimamos que esta alfarería estuvo involucrada en un sistema de comunicación visual andino más amplio y si seguimos la propuesta de Bray (2008) y Williams (2008), podemos pensar que este conjunto pudo tener una función en las estrategias de objetivación de las diferencias y la jerarquización interna de los grupos locales, en el marco de las nuevas relaciones sostenidas a partir de la expansión imperial y los consecuentes procesos de desestructuración social y política. Teniendo en cuenta que la administración inca se ejerció a través del intercambio ritual, la hospitalidad y el reasentamiento de poblaciones, también planteamos que esta cerámica fue usada por las jerarquías locales como un mediador visual en las relaciones sostenidas con los grupos trasladados por el Inka, ya que los tipos locales, como el Viluco simbolizaron al Estado inca y fueron dispositivos de transmisión de la identidad étnica entre los grupos dominados (Hayashida 1994).

Como hemos señalado, el corto lapso comprendido entre los procesos de dominación inca y española, se manifiesta en la presencia de cerámica Viluco Inca Mixto en contextos domésticos y funerarios del primer siglo de la Colonia. En este sentido, y al formar parte de una tradición cerámica andina de mayor envergadura que trascendió los tiempos prehispánicos, proponemos que las imágenes plasmadas en este conjunto cerámico con- 
tinuaron dando sentido y significado a las poblaciones locales durante la Colonia temprana. La continuidad del uso de los objetos que formaron parte de la cultura visual inca durante la Colonia, sirvió para materializar una memoria y para la supervivencia de algunas estructuras (duales, cuatripartitas, entre otras) (Cummins 2002, Timberlake 2008), por lo cual reafirmamos la idea de que las vasijas Viluco fueron "imágenes poscontacto" (Prieto Olavarría y Chiavazza 2015, en el sentido de López 2006) y dispositivos de transmisión de identidad local, que durante los primeros años de la Colonia pudieron operar tanto en el proceso de dominación como en el de resistencia, tal como propone Williams y colaboradores para el NOA (2005).

Finalmente, entendemos que en el contexto de frontera meridional hispano-indígena, la alfarería Viluco habría tenido un rol simbólico en las relaciones sostenidas con los grupos no sometidos del sur, tal como se refleja en los contextos funerarios indígenas coloniales del valle de Uco (Boman 1920; Novellino et al. 2003). En este trabajo identificamos algunas vasijas que pudieron tener algún significado en esa área limítrofe: los tres pares de vasijas gemelas hallados en Agua Amarga, las que en el contexto incaico se asociaban a los regalos que hacía el Inka a los grupos que servían al Estado; la jarra recuperada en el cementerio de Viluco, cuyo patrón decorativo ajedrezado se vincula al poder militar, la conquista y a los altos rangos del ejército inca.
Diversas preguntas quedan abiertas a las futuras investigaciones dedicadas a analizar los lenguajes visuales y el rol simbólico que tuvieron los objetos producidos por los pueblos dominados por el Inka y que siguieron usándose durante la conquista y colonia europea. Por el momento confirmamos la hipótesis de que la cerámica Viluco fue parte de los sistemas de representación visual inca, y una de las estrategias de apropiación simbólica del territorio más meridional del Imperio, y que este conjunto fue un eficiente soporte para plasmar las estrategias desarrolladas por los grupos locales para consolidar su propia identidad en períodos de dominación y transformación.

Agradecimientos Esta investigación fue financiada por el Consejo Nacional de Investigaciones Científicas y Técnicas (CONICET) (Argentina) y el Centro de Investigaciones Ruinas de San Francisco, Área Fundacional, Municipalidad de Mendoza. Nuestros agradecimientos a quienes hicieron posible el relevamiento de las vasijas en los museos: Humberto Lagiglia, Clara Abal y Juan Carlos Rusconi. A Horacio Chiavazza, por confiarnos el análisis de la cerámica Viluco del Área Fundacional y por la lectura crítica de este manuscrito. A Gabriel Cantarutti, por cedernos gentilmente las medidas de escudillas y jarras del tipo Diaguita Patrón Local Fase Inca incluidas en las Tablas 4 y 5 . A Leonardo Castillo, por su ayuda en el análisis de la cerámica Viluco. A los evaluadores, que con sus comentarios ayudaron a mejorar este trabajo.

\section{$*$ Referencias citadas}

ABAL DE RUSSO, C. 2010. Arte Textil Incaico en Ofrendatorios de la Alta Cordillera Andina. Aconcagua, Llullaillaco, Chuscha. Fundación CEPPA, Buenos Aires.

AMPUERO, G. 1986. La cultura Diaguita Chilena (1.200 a 1.470 d.C.). En Prehistoria. Desde sus orígenes hasta los albores de la conquista, J. Hidalgo, V. Schiappacasse, H. Niemeyer, C. Aldunate, I. Solimano (Eds.), pp. 277-287. Editorial Andrés Bello, Santiago.

BÁRCENA, J. R. 2002. Perspectivas de los estudios sobre la dominación Inca en el extremo austral-oriental del Kollasuyu. Boletín de Arqueología PUCP 6: 227-300.

BÁRCENA, J. R. y C. ROMÁN. 1990. Funcionalidad diferencial de las estructuras del tambo de Tambillos: resultados de la excavación de los recintos 1 y 2 de la unidad A del sector III. Anales de Arqueología y Etnología 41/42: 7-81.
BINGHAM, H. 1930. Machu Picchu, a Citadel of The Incas. Yale University Press, New Haven.

BRAY, T. 2003. Inca pottery as culinary equipment: food, feasting and gender in imperial state. Latin American Antiquity 14(1):3-28.

BRAY, T. 2004. La alfarería imperial inca: una comparación entre la cerámica estatal del área de Cuzco y la cerámica de las provincias. Chungara, Revista de Antropología Chilena 36(2): 365-374.

BOMAN, E. 1920. Cementerio indígena en Viluco (Mendoza) posterior a la conquista.Anales del Museo Nacional de Historia Natural de Buenos Aires XXX: 501-562.

BOONE, E. 2000. Stories in Red and Black: Pictorial Histories of the Aztec and Mixtec. University of Texas Press, Austin. 
BOONE, E. y M. MIGNOLO. 1994. Writing Without Words: Alternative Literacies in Mesoamerica And the Andes. Duke University Press, Durham.

CAHIZA, P. y M. J. OTS. 2005. La presencia inca en el extremo sur oriental del Kollasuyu. Investigaciones en las tierras bajas de San Juan y Mendoza, y el Valle de Uco - Rca. Argentina-. Xama 15/18: 217-228.

CANALS FRAU, S. 1946. The Huarpe. Handbook of South American Indians, Bulletin 143 1: 169-175. Smithsonian Institution Bureau of American Ethnology, Government Printing Office, Washington.

CANALS FRAU, S. 1950. Exploraciones arqueológicas en el valle de Uco (Mendoza). Publicación del Instituto de Arqueología, Lingüística y Folklore XXII: 1-28.

CANALS FRAU, S. 1956. Algunos aspectos de la Cultura Agrelo (Provincia de Mendoza).Anales de Arqueología y Etnología XII: 7-18.

CANALS FRAU, S. y J. SEMPER. 1956. La Cultura de Agrelo (Mendoza). Runa II(2), 69-180.

CANTARUTTI, G. 2002. Estadio Fiscal de Ovalle: Redescubrimiento de un Sitio Diaguita-Inca en el Valle del Limarí. Memoria de Licenciatura, Facultad de Ciencias Sociales, Universidad de Chile. Inédita.

CANTARUTTI R. G. y M. R. MERA. 2002. Alfarería del cementerio Estación Matucana: ensayo de clasificación y relaciones con la cerámica del período Inca de Chile Central y áreas vecinas. Werken 3: 147-170.

CANTARUTTI REBOLLEDO, G. y R. MERA MORENO. 2004. Estadio Fiscal de Ovalle: redescubrimiento de un sitio DiaguitaInca en el valle del Limarí. Chungara, Revista de Antropología Chilena 36(2): $833-845$

CASTILLO, L. 2013. Alfarería Indigena de Uso Doméstico en el Predio Ruinas de San Francisco del Área Fundacional de Mendoza. Publicaciones del CIRSF, Centro de Investigaciones Ruinas de San Francisco. Editorial de la Facultad de Filosofía y Letras, Universidad Nacional de Cuyo, Mendoza.

CHIAVAZZA, H. D. 2005. Los templos coloniales como estructuras funerarias. Arqueología en la Iglesia Jesuita de Mendoza. BAR International Series 1388, Oxford.

CHIAVAZZA, H. D. 2010. Ocupaciones en antiguos ambientes de humedal de las tierras bajas del norte de Mendoza: sitio Tulumaya (PA70). Intersecciones en Antropología 11(1): 47-57.

CHIAVAZZA, H. D., C. PRIETO OLAVARRÍA y V. ZORRILLA. 2010. Arqueología de una formación urbana. Los registros en una ciudad de desarrollo continuo: Mendoza en el siglo XVI. En Arqueología de Ciudades Americanas del Siglo XVI, H. Chiavazza y C. N. Cerutti (Eds.), pp. 317-342. Editorial de la Facultad de Filosofía y Letras, Universidad Nacional de Cuyo, Mendoza.

CREMONTE, M. B. 1994. Las pastas cerámicas de Potrero Chaquiago (Catamarca). Producción y movilidad social. Arqueología 4: 133-164.

CREMONTE, M. B., I. L. BOTTO, A. M. DÍAZ, R. VIÑA y M. E. CANAFOGLIA. 2007. Vasijas Yavi-Chicha: distribución y variabilidad a través de estudio de sus pastas. En Actas del XVI Congreso Nacional de Arqueología Argentina II, pp. 189-194. Jujuy.

CUMMINS, T. 2002. Toasts with the Inca. Andean Abstraction and Colonial Images on Quero Vessels. Collection: History, Languages \& Cultures of the Spanish \& Portuguese Worlds. University of Michigan Press, Ann Arbor.

CUMMINS, T. 2007. Queros, aquillas, uncus and chulpas: the composition of inca artistic expression and power. En Variations in The Expression of Inca Power, R. Burger, C. Morris, M. Matos (Eds.), pp. 267-312. Washington D.C, Dumbarton Oaks.

D'ALTROY, T., A. LORANDI y V. WILLIAMS. 1994. Producción y uso de cerámica en la economía política Inca. En Tecnología y Organización de la Cerámica Prehispánica en Los Andes, I. Shimada (Ed.) pp. 395-441. Fondo Editorial Pontificia Universidad Católica del Perú, Lima.

DEBENEDETTI, S. 1917. Investigaciones arqueológicas en los valles preandinos de la provincia de San Juan. Revista de la Universidad de Buenos Aires XIII, T. XXXII-XXXIV.

FRAME, M. 2007. Lo que Guaman Poma nos muestra, pero no nos dice sobre Tukapu. Revista Andina 44: 9-70.

FERNÁNDEZ BACA, J. 1971. Motivos de Ornamentación de la Cerámica Inca-Cuzco. Librería Studium, Lima.

GARCÍA, A. 1996. La dominación Inca en el Centro Oeste Argentino y su relación con el origen y la cronología del registro arqueológico "Viluco". Anales de Arqueología y Etnología 48/49, 57-72.

GARCÍA, A. 2007. El control incaico del área del Acequión (sur de San Juan). Actas XVI Congreso Nacional de Arqueología Argentina. Tomo II: 487-491, Jujuy.

GONZÁLEZ CARVAJAL, P. 1998. Doble reflexión especular en los diseños cerámicos Diaguita-Inca: de la imagen al símbolo. Boletín del Museo Chileno de Arte Precolombino 7:39-52.

GONZÁLEZ CARVAJAL, P. 2004a. Patrones decorativos y espacio: el arte visual diaguita y su distribución en la cuenca del río Illapel. Chungara, Revista de Antropología Chilena 36(2): 767-781. 
GONZÁlEZ CARVAJAL, P. 2004b. Arte visual, espacio y poder: manejo incaico de la iconografía cerámica en distintos asentamientos de la fase Diaguita Inca en el valle de Illapel. Chungara, Revista de Antropología Chilena 36(2): 375-392.

GONZÁLEZ CARVAJAL, P. 2008. Mediating opposition: on redefining Diaguita visual codes and their social role during the Inca Period. En Lenguajes Visuales de Los Incas, P. González Carvajal, T. Bray (Eds.), pp. 9-33. BAR International Series 1848, Oxford.

GONZÁLEZ CARVAJAL, P. 2013. Arte y cultura diaguita chilena: simetría, simbolismo e identidad. Ucayali Editores, Santiago.

GONZÁLEZ CARVAJAL, P., T. BRAY. 2008. Visual Languages of the Inca. En Lenguajes Visuales de Los Incas, P. González Carvajal, T. Bray (Eds.), pp. 1-8. BAR International Series 1848, Oxford.

GOSSELAIN, O. 1998. Social and technical identity in a clay crystal ball. En The Archaeology of Social Boundaries, M. Stark (Ed.), pp. 78-106. Smithsonian Institution Press, Washington D.C.

HAYASHIDA, F. 1994. Producción cerámica en el imperio Inca: una visión global y nuevos datos. En Tecnología y Organización Cerámica en Los Andes, I. Shimada (Ed.), pp. 433-475. Fondo Editorial Pontificia Universidad Católica del Perú, Lima.

JACKSON, M. 2008. Moche Art And Visual Culture in Ancient Perú. University of New Mexico, Albuquerque.

LAGIGLIA, H. 1978. La Cultura de Viluco del Centro Oeste Argentino. Revista del Museo de Historia Natural III(1-4): 227-265.

LAGIGLIA, H. 1980. El proceso de agriculturización del sur de Cuyo: la Cultura de Atuel II. Actas del V Congreso Nacional de Arqueología Argentina: 231-252.

LAGIGLIA, H. 2000 Ms. La Cultura de Viluco. Revista del Museo de Historia Natural de San Rafael, Mendoza. Inédito.

LÓPEZ, M. A. 2006. Imágenes postconquista y etnogénesis en la Quebrada de Humahuaca, Jujuy, Argentina. Hipótesis de trabajo arqueológico. Memoria Americana 14: 167-202.

MARTÍNEZ CERECEDA, J. 2008. Pensar y representarse: aproximaciones a algunas prácticas coloniales andinas de los siglos XVI y XVII. En Lenguajes Visuales de Los Inca, P. González Carvajal, T. Bray (Eds.), pp. 147-161. BAR International Series 1848, Oxford.

MICHIELI, T. C. 1974. Arqueología de Mendoza en el período cerámico (entre los ríos Mendoza y Tunuyán). Seminario de Licenciatura. FFyL, Universidad Nacional de Cuyo. Inédita.

MICHIELI, T. C. 1983. Los Huarpes Protohistóricos. Imprenta de la Universidad Nacional de San Juan, San Juan.
MICHIELI, T. C. 1990 . Textilería Incaica en la provincia de San Juan: los ajuares de los cerros Mercedario, Toro y Tambillos. Instituto de Investigaciones Arqueológicas y Museo UNSJ, San Juan.

MICHIELI, T. C. 1998. Aproximaciones a la identificación de una cerámica indígena posthispánica del sur de San Juan. Publicaciones 22: 55-76.

MICHIELI, T. C. 2015. Arqueología de Angualasto: historia, ruinas y cóndores. Editorial de la Facultad de Filosofía, Humanidades y Artes, Universidad Nacional de San Juan.

MORRIS, C. 1995. Symbols to power. Styles and media in the Inca State. En Style, Society and Persons: Archaeological and Ethnological Perspectives, C. Carr, J. Nietzel (Eds.), pp. 419-433. Plenum Press, New York.

MULVANY, E. 2004. Motivos de flores en keros coloniales: imagen y significado. Chungara, Revista de Antropología Chilena 36(2): 407-419.

NOVELLINO, P., V. DURÁN y C. PRIETO. 2003. Cápiz Alto: aspectos bioarqueológicos y arqueológicos del cementerio indígena de época pos-contacto (provincia de Mendoza, Argentina). Revista española de Paleopatología 1: 1-16.

OTS, M. J. 2008. Aportes del Análisis Petrográfico de Cortes Delgados para la Caracterización y Clasificación del Estilo Cerámico Viluco Inka. Boletín del Laboratorio de Petrología y Conservación Cerámica, año 1, 1(2): 12-21.

PÁEZ, M. y M. ARNOSIO. 2009. Inclusiones piroclásticas en pastas cerámicas del valle de Tafí (Tucumán, Argentina): implicancias para las prácticas de producción. Estudios Atacameños. Arqueología y Antropología Surandinas 39: 5-20.

PARISII, M. 1994. Algunos datos de las poblaciones prehispánicas del Norte y Centro Oeste de Mendoza y su relación con la dominación Inca del área. Xama 4-5: 51-69.

PRIETO, M. R. 2000 [1983]. Formación y consolidación de una sociedad en un área marginal del Reino de Chile: la Provincia de Cuyo en el siglo XVII. Tesis Doctoral, FFyL, Universidad Nacional de Cuyo. Número especial de los Anales de Arqueología y Etnología 52/53.

PRIETO OLAVARRÍA, C. 2010 a Ms. La especialización artesanal alfarera de la Cultura Viluca. Norte y Centro de la Provincia de Mendoza. Tesis Doctoral, Facultad de Filosofía y Humanidades, Universidad Nacional de Córdoba. Inédita.

PRIETO OLAVARRÍA, C. 201ob. La cerámica del cementerio de Cápiz Alto (Departamento de San Carlos, Mendoza). Una aproximación a las identidades culturales. Anales de Arqueología y Etnología 63/64: 151-175.

No $55 / 2017$

ESTUDiOS ATACAMEÑOS

Arqueología y Antropología Surandinas 
PRIETO OLAVARRÍA, C. 2012 La producción y función de la cerámica indígena durante la dominación incaica y la colonia en Mendoza (Argentina). Intersecciones en Antropología 13: 71-87.

PRIETO OLAVARRÍA, C. 2013 La presencia indígena en la ciudad de Mendoza en los siglos XVI y XVII. Análisis desde la evidencia cerámica y etnohistórica. En Actas del V Congreso Nacional de Arqueología Histórica Argentina 2, pp. 9-39. Editorial Académica Española, Saarbrücken.

PRIETO, C., H. CHIAVAZZA. 2009. La producción cerámica Viluco entre los siglos XV y XVII (Provincia de Mendoza, Argentina). Chungara, Revista de Antropología Chilena 41(2): 261-274.

PRIETO OLAVARRÍA, C. y H. CHIAVAZZA. 2010. La alfarería Viluco y los contextos del Área Fundacional. Aportes al estudio de la dominación incaica y los primeros años de la Colonia en el Valle de Mendoza. En Actas del XVII Congreso Nacional de ArqueologíaArgentina II, pp. 807-812. Mendoza.

PRIETO OLAVARRÍA, C. y H. CHIAVAZZA. 2015. Cambios en contextos de colonización: opciones económicas y transformaciones tecnológicas en el norte de Mendoza entre los siglos XV y XVII (Rca. Argentina). Vegueta. Anuario de la Facultad de Geografía e Historia 15: 159-184.

PRIETO OLAVARRÍA, C. y B. CASTRO DE MACHUCA. 2015. Resultados preliminares del análisis petrográfico de la cerámica de los períodos agroalfarero medio y tardío del Norte de Mendoza. Xama, Serie Monografías 5: 79-94.

PRIETO OLAVARRÍA, C., M. C. PÁEZ. 2015. Presencia de inclusiones piroclásticas en la cerámica de los siglos XV a XVII en el Centro Oeste y Noroeste Argentino. Chungara, Revista de Antropología Chilena 47(3): 441-453.

PRIETO OLAVARRÍA, C. y B. CASTRO DE MACHUCA. 2017 Petrographic characterization and identification of temper sources in local ceramics during the Inca domination and early Spanish colony (Mendoza, west-central Argentina). Journal of Archaeological Science Reports 13: 351-360.

PRIETO OLAVARRÍA, C., B. CASTRO DE MACHUCAy L. PUEBLA. 2010. Vitroclastos en la cerámica Viluco. Estudios petrográficos en la cerámica Viluco y colonial del norte de Mendoza. Boletín del Laboratorio de Petrología y Conservación Cerámica 2(2): 1-8.

PRIETO OLAVARRÍA, C., H. CHIAVAZZA, V. PORTA y E. BONTORNO. 2016. Variabilidad alfarera y procesos ambientales en un sitio de límite cultural. Estilos tecnológicos de la cerámica del río Desaguadero (PA68) (Mendoza, Centro Oeste Argentino). Relaciones de la Sociedad Argentina de Antropología XLI 1: 131-150.
QUISPE-AGNOLI, R. 2005. Cuando occidente y los Andes se encuentran: qellqay, escritura alfabética y tokhapu en el siglo XVI. Colonial Latin American Review 14(2): 263-298.

QUISPE-AGNOLI, R. 2008. Para que la letra lo tenga en los ojos. En Lenguajes Visuales de Los Incas, P. González Carvajal, T. Bray (Eds.), pp. 121-133. BAR International Series 1848, Oxford.

RAFFINO, R. 1981. Los Incas del Kollasuyu. Origen naturaleza y transfiguraciones de la ocupación Inca en los Andes Meridionales. Ramos Americana Editora, Buenos Aires.

RICE, P. 1987. Pottery Analisys: A Source Book. University of Chicago Press, Chicago and London.

ROWE, J. 1946. Inca culture at the time of the Spanish Conquest. En Handbook of South American Indians Bulletin 143, H. Steward (Ed.), pp. 183-330. Washington D.C.

RUSCONI, C. 1962. Poblaciones Pre y Posthispánicas de Mendoza, vol. III Arqueología, Mendoza.

RUSCONI, C. 1964. Hallazgos antropológicos en Maipú (Mendoza). Revista del Museo de Historia Natural de Mendoza XVI: 45-57.

RUSCONI, C. 1956. Descubrimiento arqueológico en Godoy Cruz (Mendoza). Revista del Museo de Historia Natural de Mendoza IX: 87-97.

RUSCONI, C. 1967. Restos indígenas hallados en una excavación de Las Heras (Mendoza). Revista del Museo de Historia Natural de Mendoza XIX: 3-13.

SHEPARD, A. 1956. Ceramic for The Archaeologist. Carnegie Institution of Washington, Washington DC.

SALOMON, F. 2001. How an andean "writing without words" works. Current Anthropology 42(1): 1-27.

SCHOBINGER, J. (Comp.) 2001. El Santuario Incaico del Cerro Aconcagua. Editorial de la Universidad Nacional de Cuyo, Mendoza.

SILVERMAN, G. 2011. La escritura Inca: la representación geométrica del quechua precolombino. Revista D'Història i Humanitats Ex Novo 7: 37-49.

TIMBERLAKE, M. 2008. Tocapu in a colonial frame: andean space and the semiotics of painted colonial tocapu. En Lenguajes Visuales de Los Incas, P. González, P. Carvajal, T. Bray (Eds.), pp. 165-181. BAR International Series 1848, Oxford.

TOBAR, V. 2013 Ms. Los diseños decorativos de la cerámica Viluco (siglos XV-XVII): una aproximación a los lenguajes visuales locales. Tesina de Licenciatura. FFYL, Universidad Nacional de Cuyo. Inédita. 
URIBE RODRÍGUEZ, M. 1998. La cerámica de Arica 40 años después de Dauelsberg. Chungara, Revista de Antropología Chilena 31(2): $189-228$.

WASHBURN, D. 1983. Structure and cognition art. Cambridge University Press.

WASHBURN, D. 1987. The neighbor factor: basket designs in northern and central California. Journal of California and Great Basin Anthropology 9(2): 146-173.

WASHBURN, D., D. CROWE. 1988. Symmetries of Culture. Theory and Practice of Plane Pattern Analysis. University of Washington Press.
WILLIAMS, V. 2008. Espacios conquistados y símbolos materiales del Imperio Inca en el Noroeste de Argentina. En Lenguajes Visuales de los Incas, P. González Carvajal y T. Bray (Eds.), pp. 35-58. BAR International Series 1848, Oxford.

WILliAMS, V., P. VILlEGAS, M. GHEGGI y M. CHAPARRO. 2005. Hospitalidad e intercambio en los valles mesotermales del Noroeste argentino. Boletín de Arqueología PUCP 9:335-372. 
